شبكة الثكل الجانبي للقياسات الجسمية للاعبي الوثب الطويل على النى وفق التأثير في مستوى الإنجاز

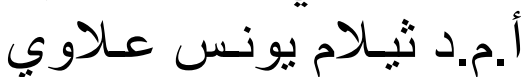

جامعة الموصل / كلية التربية الرياضية

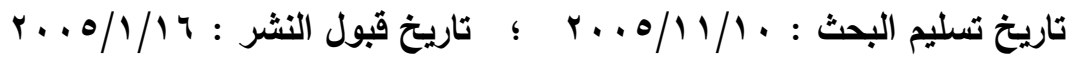

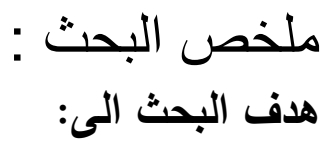

- تحديد أهمية مكونات القياسات الجسمية من أطوال ومحيطات وأعراض وسمك الثنايا الجلدية المؤثرة في الإنجاز بالوثب الطويل.

- وضع معادلات للتتبؤ لمكونات القياسات الجسمية في الإنجاز بالوثب الطويل.

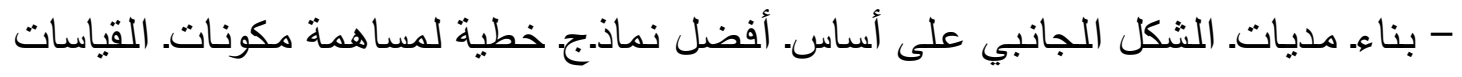

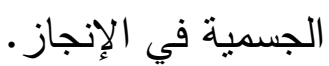

- تحديد شبكة الثكل الجانبي للقياسات الجسمية للمتفوقين وغير الدتفوقين على وفق التأثير

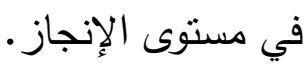

ونكونت العينة من (10) لاعبا يمنلون الأندية العراقية ، فيما مثلت متغيرات البحت (9 (1) قياسا جسميا بالإضافة الى مستوى الإنجاز

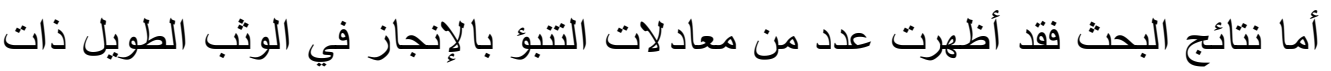

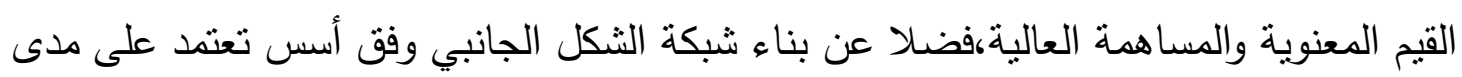

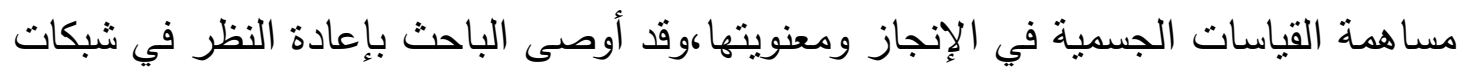
الثكل الجانبي الني أعدت سابقاً ولمختلف الألعاب.

\title{
The profile of the anthropometric measurements for a long jump players According to the effect of the performance level
}

\section{Asst. Prof . Dr .Thelam Younis Allawi \\ University of Mosul - College of Sport Education}

\section{Abstract:}

The research aims:

- To determine the importance of anthropometric measurements which include (length, circumferences, breadths, and skin fold) which affect the performance of long jump players. 
- Setting equations to predict the component of anthropometric measurements in long jump .

- Constricting the profile range on the a bases through best linier models sharing the anthropometric measurements elements in performance.

- Determine the anthropometric measurements profile of high and low level players in accordance to the level of performance.

The research sample included (15) long jump players represent Iraqi clubs. while data collection representing (19) measurement, in additional to the measurement of performance level.

The result of the research reveals number of significant equations for the long jump performance. as well as constructing the profile on the share of anthropometric measurements of performance and its significant.

The researcher recommend to repeat the profiles which was billed formerly for different cams.

$$
\text { المقدمة و أهمبة البحث: : }
$$

فعالية الموثب الطويل هي أحدى فعاليات. الساحة و.للميدان. التي لا. تختلف عن بقية

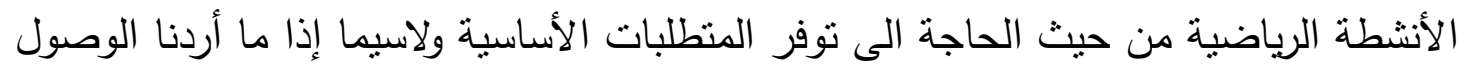

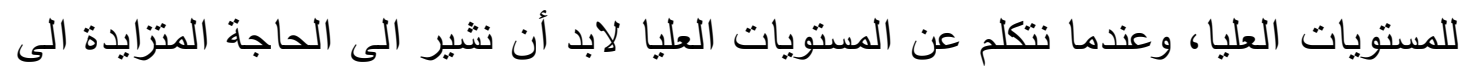

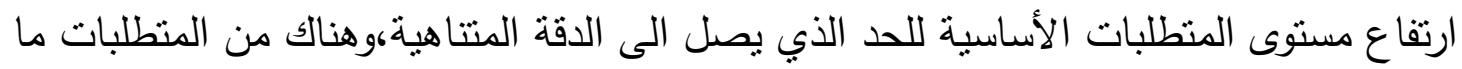

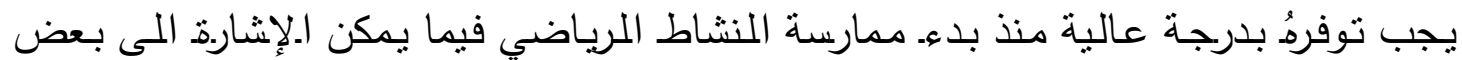
المنطلبات التي يمكن أن نكتفي بالحدود الدنيا لها-في بداية الأمر - وذللك لإمكانية نطويرها

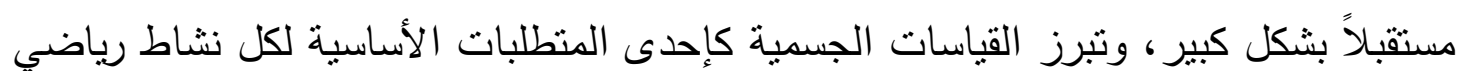

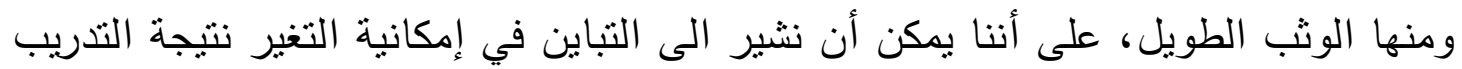

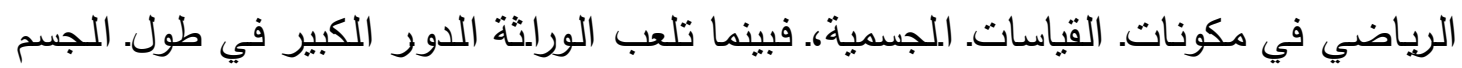
وأطرافه، يقوم التدريب الرياضي بدوره في تطوير محيطات وأعراض الجسم ووزنهِ، "فالأحمال والمجهودات الجسمية تؤدي الى تكيف وظيفي وتكويني والى التغيرات في الأعضاء الداخلية ينتج

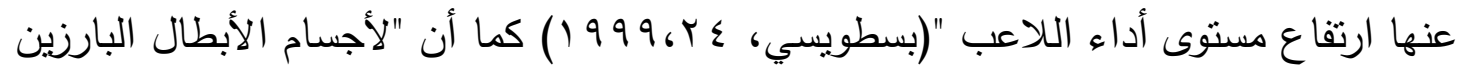


تكوينات جسمانية معينة تتناسب ونوع النشاط الرياضي التخصصي، وهذا التكوين الجسماني

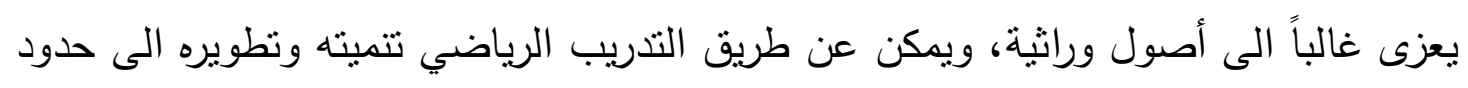

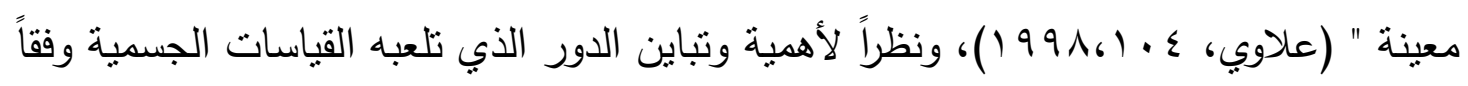

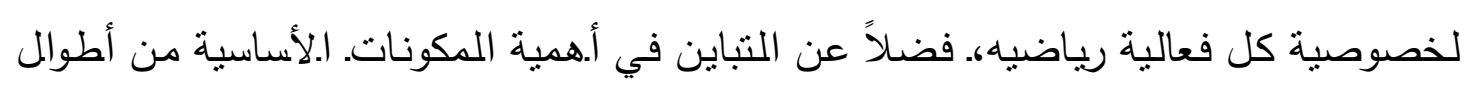

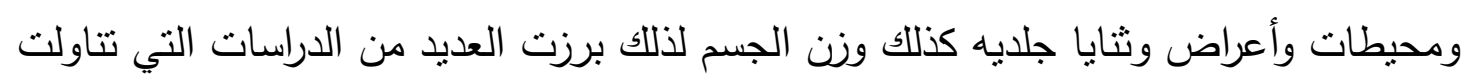

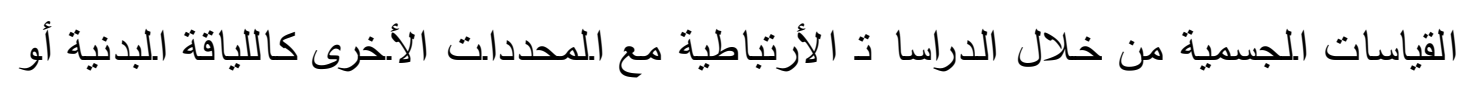

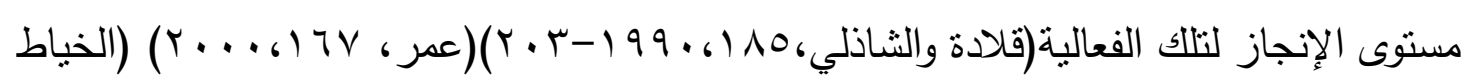
وعلاوي، (Y9V، (99))، وقد حددت هذه الدراسات مقدار التباين الكمي في مستوى الإنجاز نتيجة

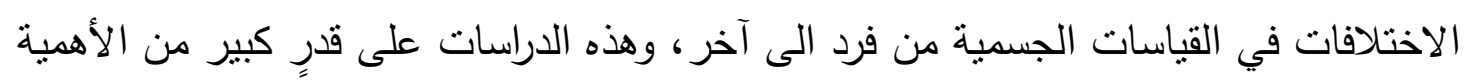

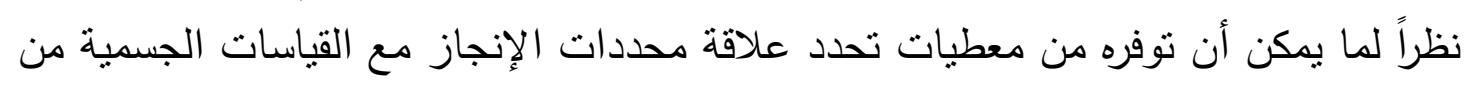

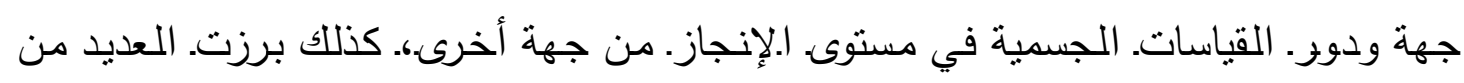

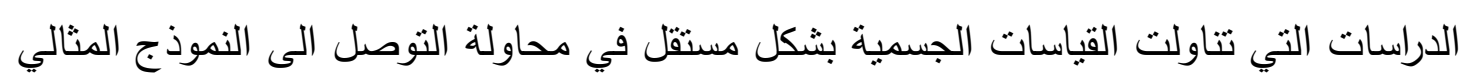

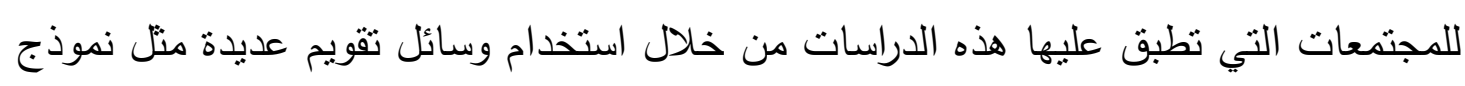

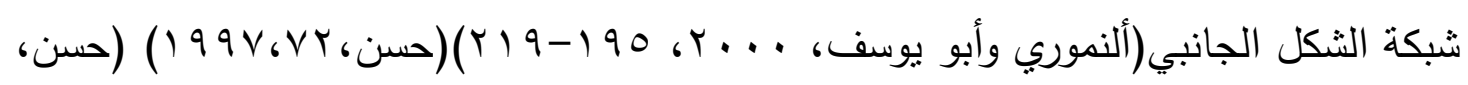
جr (، 1991)، ، كما إن نموذج شبكة الثكل الجانبي يمكن أن يوفر لنا نموذجاً تقويمياً يمكننا

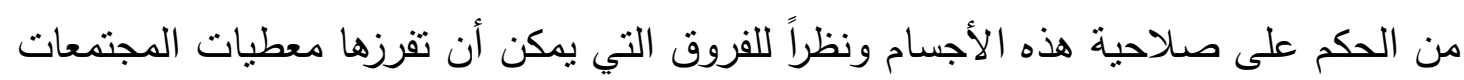
المختلفة وأهمية القياسات الجسمية لذلك تبرز أهمية تناول هذين الجانبين بالدراسة على الإنى عينة

$$
\text { تمنل لاعبي الوثب الطويل. }
$$

مشكلة البحث: : مئر

نظراً لأهية بعض الوسائل الإحصائية في توضيح وتحديد دور محددات الإنجاز العالي

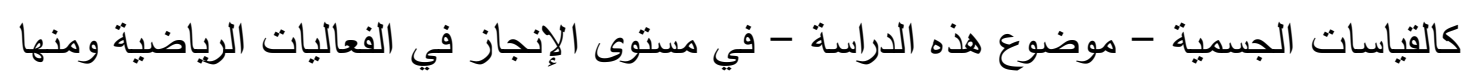

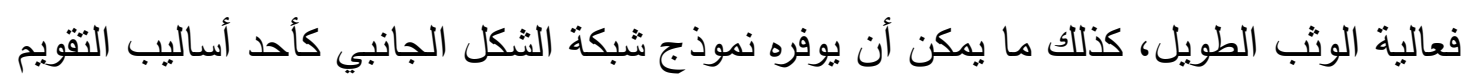

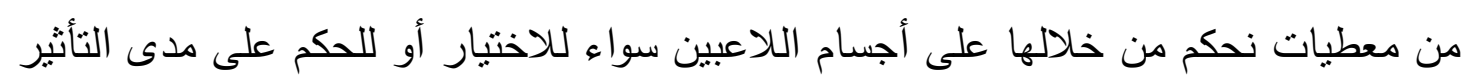

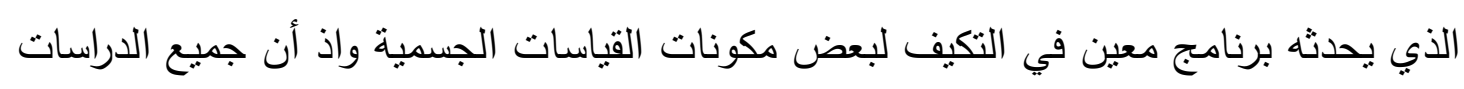

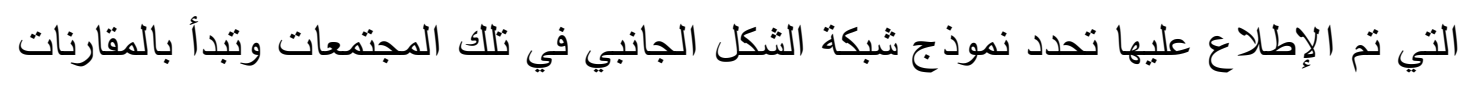
بين اللاعبين على أساس هذا النموذج من دون الأخذ بنظر الاعتبار الناحية الارتباطية للقياسات

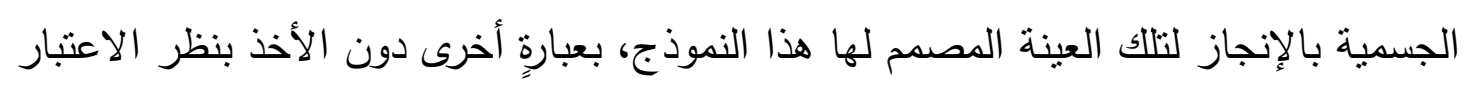

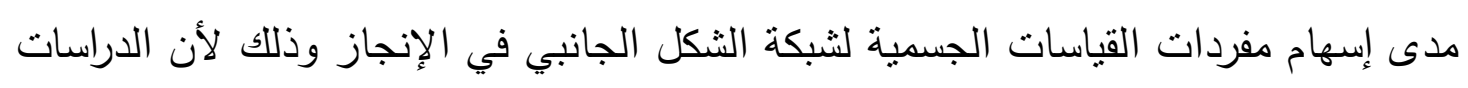

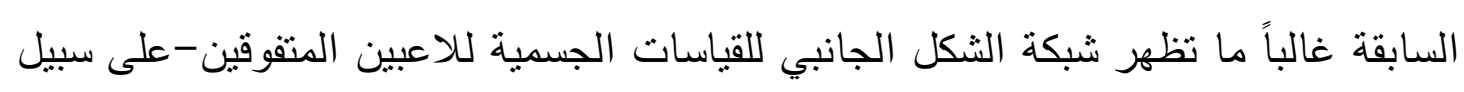


المثال- على أنهم ذوي القيم الكمية المرتفعة للقياسات الجسمية، أو على أقل تقدير لا تخوض التها

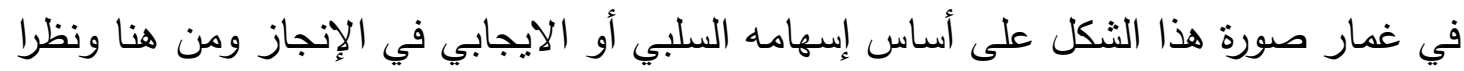

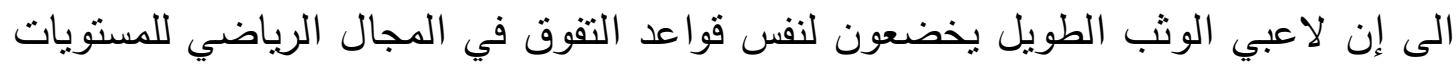

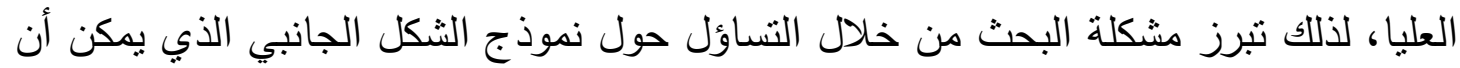

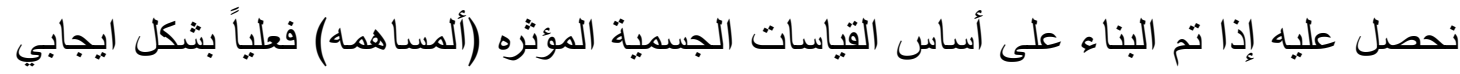
أو سلبي في مستوى الإنجاز .

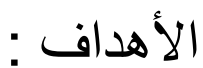

- تحديد أهية مكونات القياسات الجسمية من أطوال ومحيطات وأعراض وسمك الثنايا الجلدية المؤثرة(ألمساهمه) في الإنجاز بالوثب الطويل.

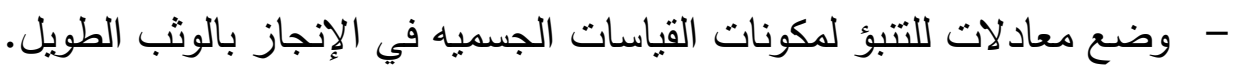

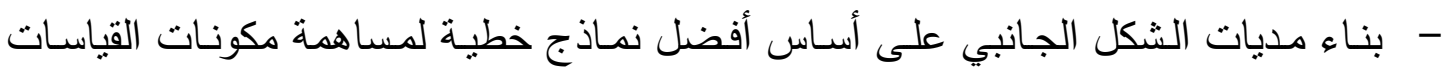

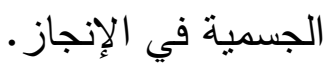

- - تحديد شبكة الثكل الجانبي للقياسات الجسمية للمتفوقين وغير المتفوقين على وفق التأثير

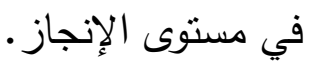

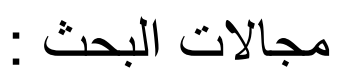

- المجال البشري: لاعبو الوثب الطويل المتقدمين في العراق.

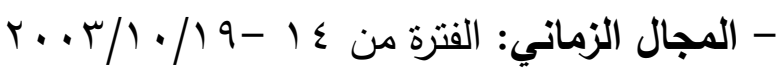
- المجال المكاني: ملعب وقاعات كلية النربية الرياضية في بغداد.

تحديد المصطلحات : - اللاعبون المتفوقون : هم اللاعبون اللذين يحققون المراكز الثلاثة الأولى في بطولة الانديه العراقية . - اللاعبون غير المتفوقين: هم اللاعبون اللذين يحققون المراكز من الرابع وحتى الأخير في بطولة الانديه العراقية . 
الدر اسات النظرية و البحوث المشابهه :

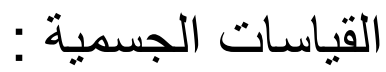

هي العلم الذي يدرس قياسات الجسم الإنساني وأجزائه وإظهار الاختلافات التركيبية فيه(73, أو هو العلم الذي يبحث في قياس جسم الإنسان من الخارج،

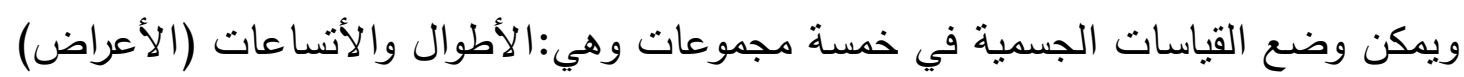

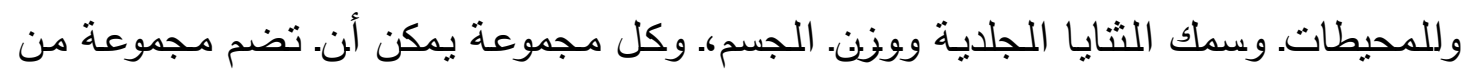

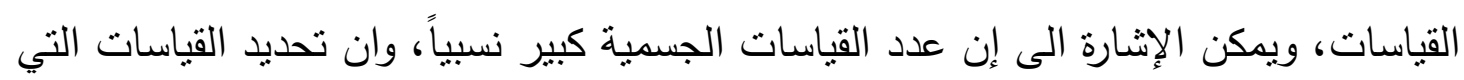

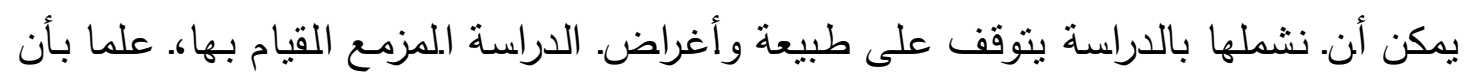

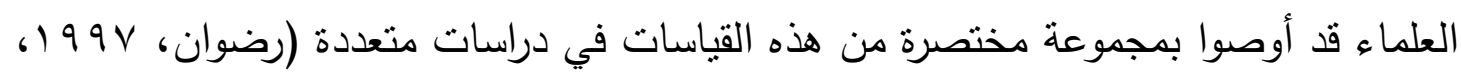
$\cdot(r q-r$.

إن القياسات الجسمية الخاصة بالمستويات العليا يمكن الحصول عليها عن طريق الوراثة

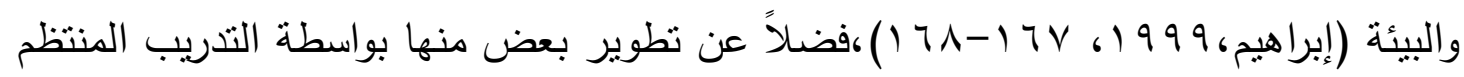

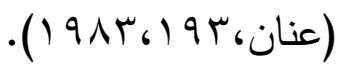

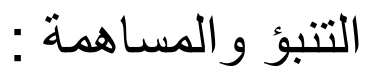

إن التلازم في التغير باتجاه واحد بين متغيرين قد يساعد في التتبؤ باحداهما من خلال

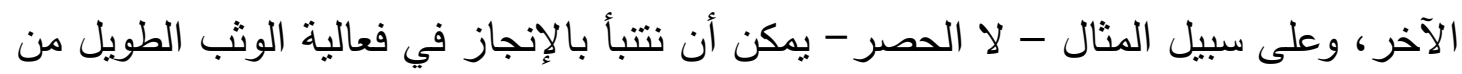

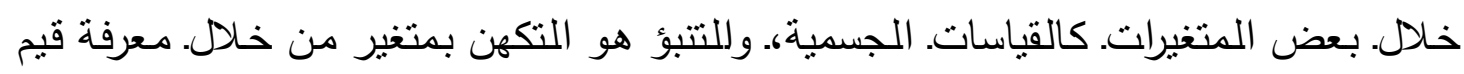

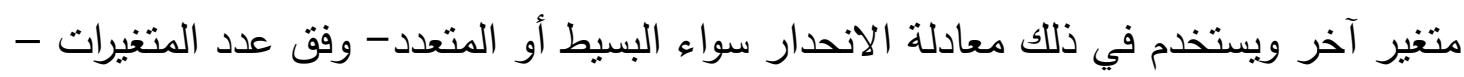
والتي تمكننا من "بيان طبيعة العلاقة الموجودة بين المتغيرين في تقدير قيمة أحدهما (المتغير التابع) إذا عرفت قيمة الآخر (المتغير المستقل) وبالطبع تتوقف دقة التونة التقديرات التي تعطيها معادلة الانحدار المتعدد على دقة العلاقة الموجودة بين المتغيرين، فكلما كانت هذه العلاقة قوية العاية

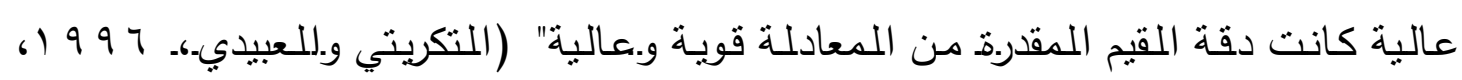

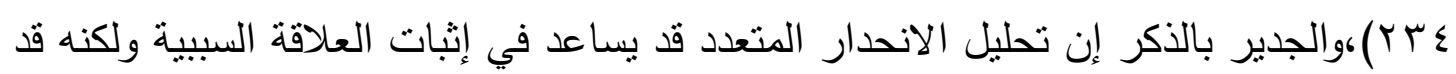

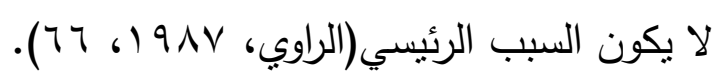

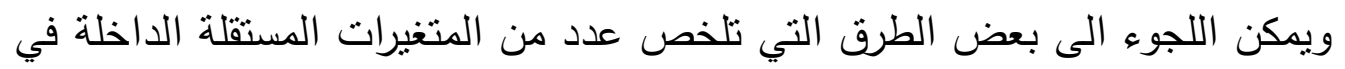

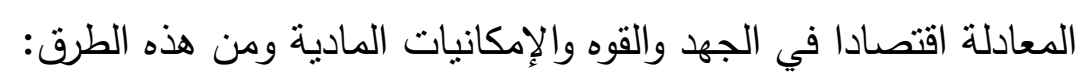

- طريقة كل الانحدارات الممكنة وتقوم على إعطاء معادلة النموذج لكل المتغيرات الداخله. - طريقة الحذف العكسي(الخلفي) وتقوم على حذف المتغيرات الغير مهمة بالتدريج. - طريقة الاختيار المباشر (الأمامي) وتقوم على اختيار المتغيرات المهمة فالأقل أهميه . 


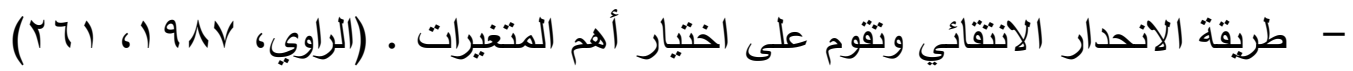

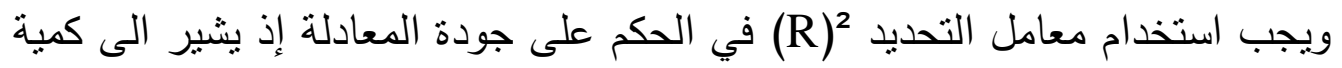

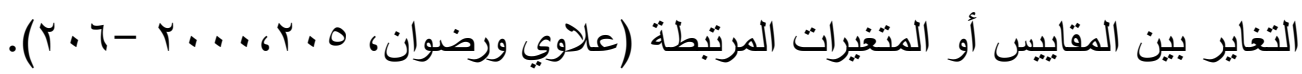

الشكل الجانبي كوسيلة للتقويم : يتميز التقويم الحديث بتعدد. أدو.لته فضلاً عن ارتفاعـ معدلات. المصدقـ و.للثبات

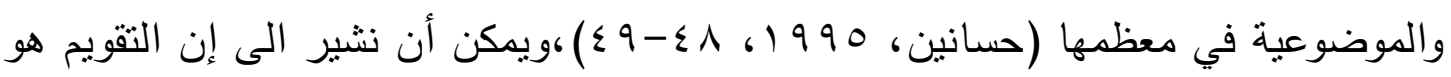

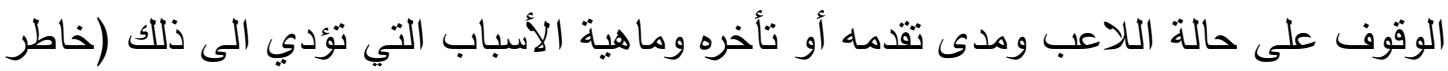

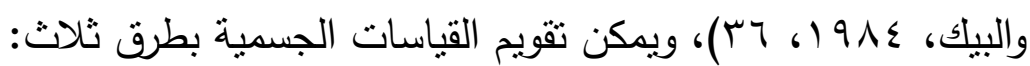
- - مريقة المستويات الجسمية - - - طريقة العلاقات (الارتباط المنبادل)

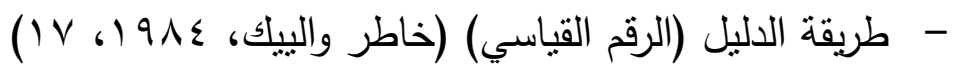
وينتمي أسلوب الثكل الجانبي الى طريقة المستويات الجسمية، وهي في الواقع دلالات

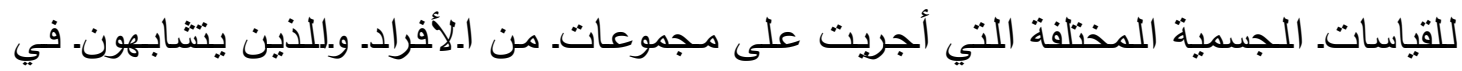

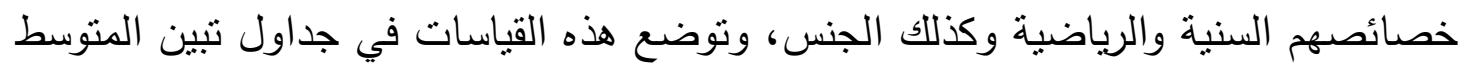

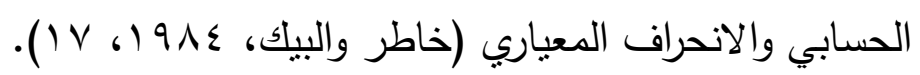
وتتكون شبكة الثكل الجانبي من خانة عمودية تتقسم بوساطة خط المتوسط الذي يمنل المتوسطات المتلى الى قسمين،قسم لجهة اليمين، والآخر لجهة اليسار - يحدد انحراف قياسات الشخص عن المنوسط وحتى \pm نصف انحراف.--ويوجد خانتان. على كل جانب من الخانة الوسطى وذلك لتحديد زيادة قياسات الثخص عن المتوسط الأمنل أو نقصانها، ومن ثم تأني

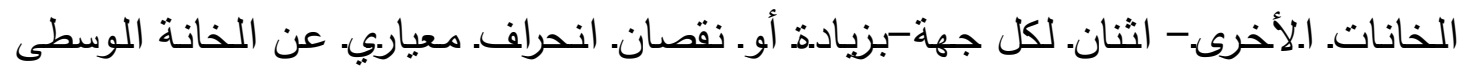

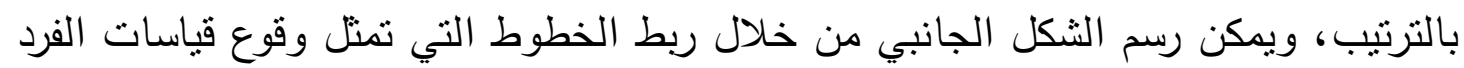

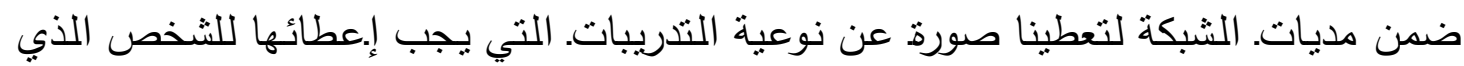

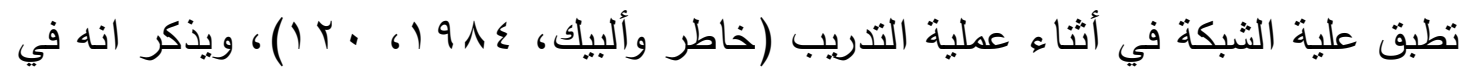
البحوث التي تتثمل على الثكل الجانبي فأن أنماط القياس يجب أبن تتنتمل على المكونات

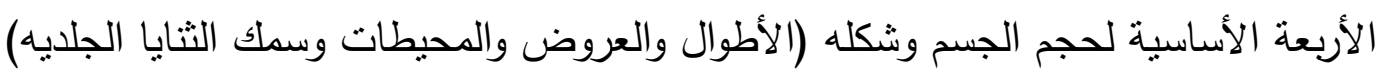

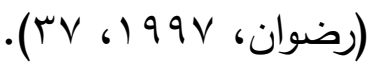


الدر اسات المشابهة : مابهة

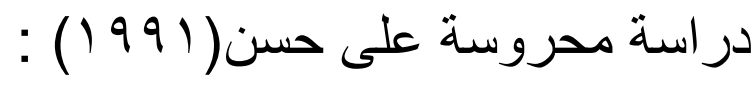

"تحديد المعدلات النموذجية لثبكة الثكل الجانبي لبعض القياسات الجسمية لتحقيق المستوى : لبهى العالي للاعبي سلاح الثيش بالمبارزة"

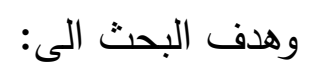

- التعرف على مواصفات بعض القياسات الجسمية لدى لاعبي المبارزة الدوليين والتي يمكن أن تستخدم دليلاً لتصحيح شبكة الثكل الجانبي.

- التعرف على أفضل أسلوب إحصائي لتصميم شبكة الثكل الجانبي لبعض القياسات الجسمية للاعبي المبارزة الدوليين بين الأسلوبين المئيني ومتوسطات المتغيرات وانحرافاتها.

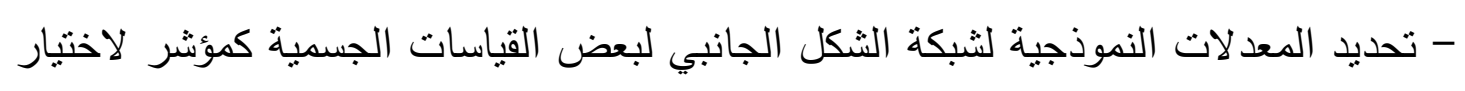
لاعبي المبارزة الدوليين في المراحل السنية المختلفة لتحقيق المستوى العالي.

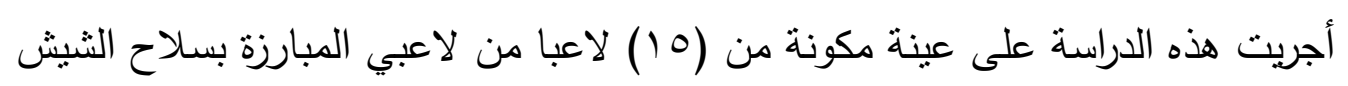

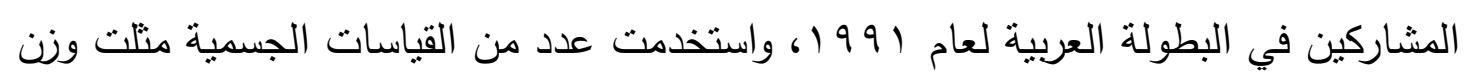
الجسم وسبعة قياسات. لأطوال. الجسم وثلاث قياسات للأعراض ونت استخدام. طريقتي الثكل الجانبي والمئينيات اللتنين تعتمدان على الوسط الحسات الجسابي والانحراف المعياري.

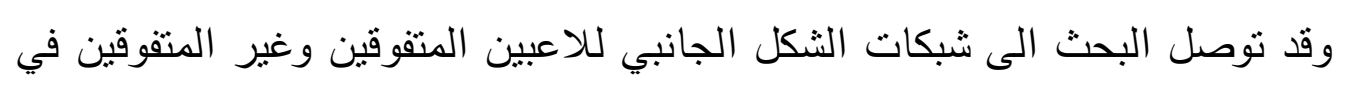

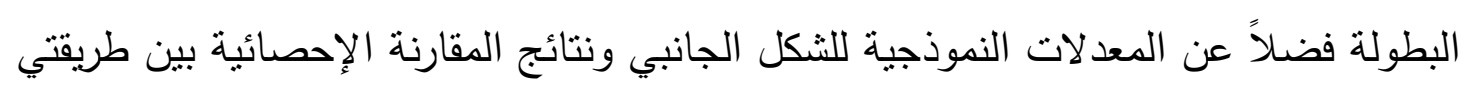
الثكل الجانبي فضلاً عن بعض القياسات الجسمية المميزة للاعبين المتفوقين في نتائج مسابقة

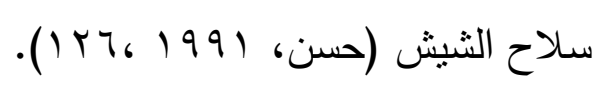

در اسة أحمد إسماعيل عبد الله ياسين الطائي (r . . r م) :

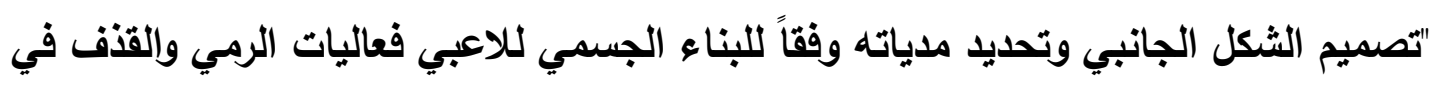

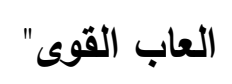

$$
\text { وهدف البحث الى: }
$$

- وضع مديات للثكل الجانبي للقياسات الجسمية لكل فعالية من فعاليات الرمي والقذف للاعبين

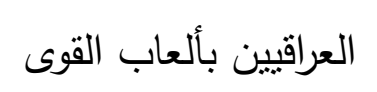

- تصميم شبكة الثكل الجانبي للقياسات الجسمية للاعبين المتفوقين وغير المتفوقين لكل فعالية

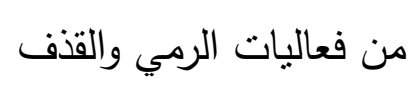

\section{rYT}


- التعرف على القياسات الجسمية المميزه للاعبي كل فعالية من فعاليات الرمي والقذف قياساً ببقية الفعاليات من خلال شبكة الثكل الجانبي

وتكونت العينة من (r \&) لاعب يمنلون الفعاليات الأربعة، ونم جمع البيانات بوساطة

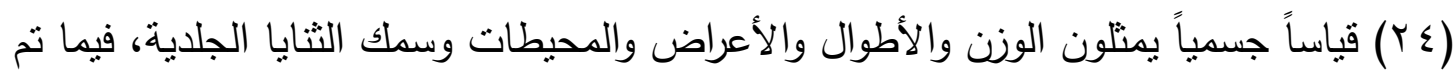

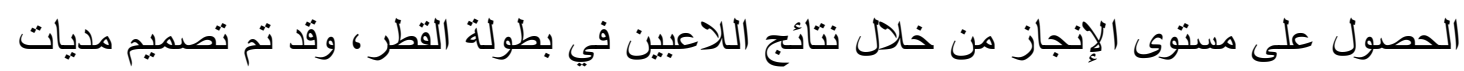
الثكل الجانبي للقياسات الجسمية من خلال مؤشرات الوسط الحسابي والاتحراف المعياري. وقد تم اللتوصل المى المديات. وشبكات. الشكل اللجانبي للقياسات. اللجسمية للاعبين المتفوقين وغير المتفوقين في مستوى الإنجاز فضلاً عن بعض القياسات التي عكستها مديات

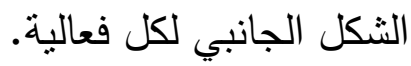

مناقشة الدر اسات المشابهه : إن أهداف الدراسات المشابهه تصب في أهداف البحث الحالي فضلاً عن إيجاد الإسهام

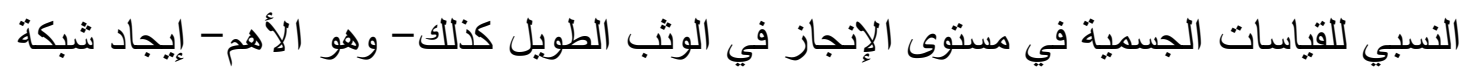

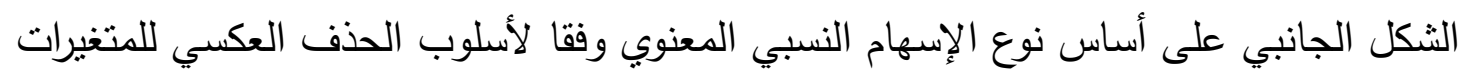

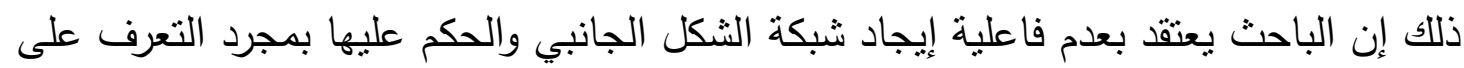
مواصفات. المتفوقين و.غير المتفوقين وبذلك تختلف هذه اللدراسة في طريقة تحديد القياسات الجسميه الداخلة في بناء الثنكل الجانبي.

$$
\text { الجر اعات البحث: نم استخدام المنهج الوصفي بالأسلوب الأرتباطي }
$$

العينة: اختيرت العينة بالأسلوب العدي، وتكونت من لاعبي القطر المتقدمين المشاركين في

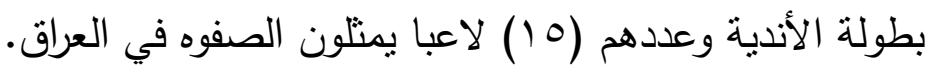

وسائل جمع البيانات: تكونت من القياسات الجسمية ومستوى الإنجاز الذي تم تحقيقه في بطولة الأندية العراقية.

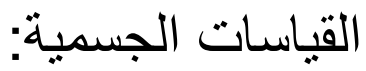

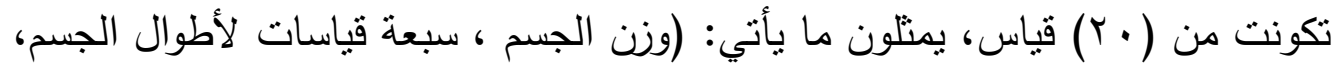

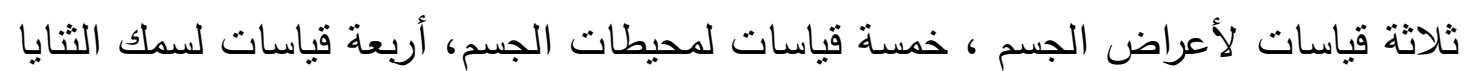




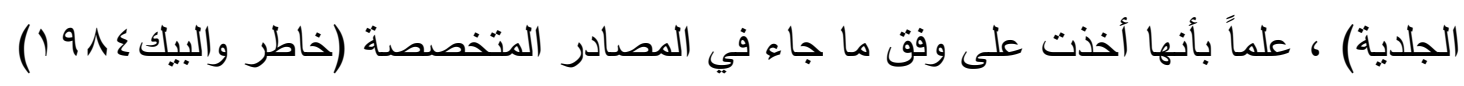

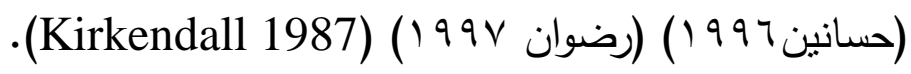

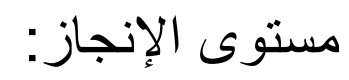

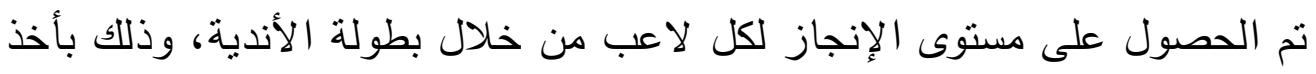

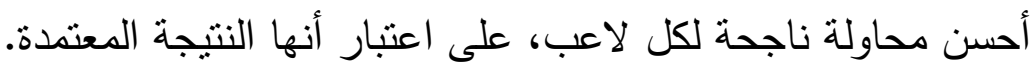

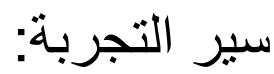

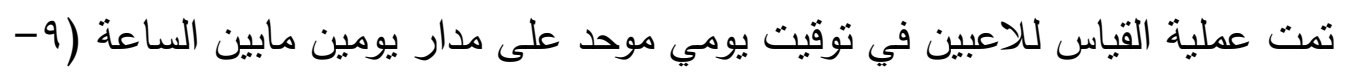
(1) صباحاً، فيما تم الحصول على الإنجاز من قوائم حكام البطولة وبنفس اليوم.

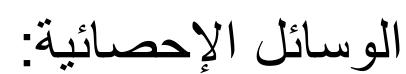

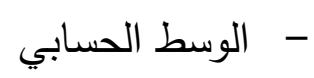

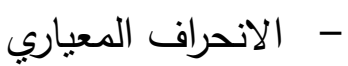

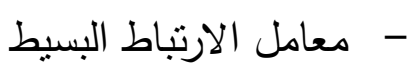

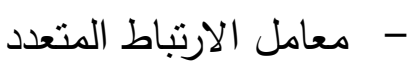

- - تحليل الانحدار المتعدد بطريقة كل الانحدارات الممكنة All Possible Regression Procedure.

The Back ward Elimination Procedure.

- تحليل الانحدار المتعدد بطريقة الحذف العكسي - تحليل الانحدار المتعدد بطريقة الانحدار الانتقائي

Stepwise Regression Selection .

وقد تمت جميع المعالجات الإحصائية باستخدام النظام الإحصائي SPSS. 
عرض النتائج وتحليلها ومناقتنتها:

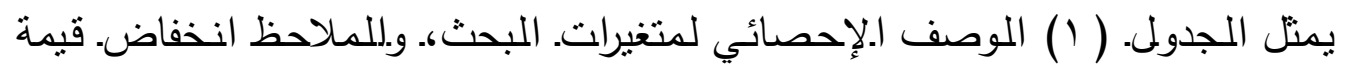

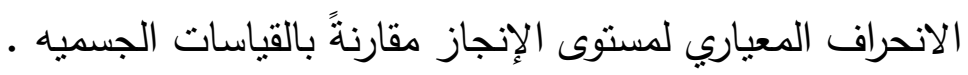

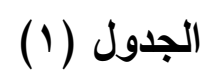

الوصف الإحصائي للقياسات الجسمية والإنجاز للاعبي الوثب الطويل

\begin{tabular}{|c|c|c|c|c|c|c|}
\hline أوطأ قيمة & أعلى قيمة & الانعراف & الوسابي & القياس & المتغيرات & $ت$ \\
\hline Tr & $\Lambda \cdot, 0$ & $0, Y_{1}$ & $v \cdot, v_{0}$ & كغم & الوزن الوزن & 1 \\
\hline$|v|$ & IAV & $\varepsilon, \varepsilon \varepsilon$ & IVV, qY & سم سم & طول الجسم & r \\
\hline$\wedge \wedge$ & 99 & r,Or & $9 r, \cdot \varepsilon$ & 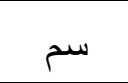 & طول الجذع مع الرأس & $r$ \\
\hline$V Y, O$. & ᄉr,o. & ז, . & $V V, 19$ & سم سم & طول الذراع مع الكف & $\varepsilon$ \\
\hline 94 & $1 \cdot Y, 0$. & $r, 90$ & $90,1 Y$ & سم سم & طول الرجل & 0 \\
\hline$r \varepsilon, 0$ & $r$. & 1,74 & $r v, 11$ & 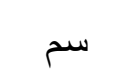 & طول القدم & 7 \\
\hline$\varepsilon \cdot, \wedge$ & $\leq 0,9$ & $1,0 \mathrm{~V}$ & $\varepsilon r, \wedge r$ & سم & عرض الكتقين & $\checkmark$ \\
\hline$r V, r$ & (ז, & $r, \cdot V$ & & سم & عرض الوركين & $\wedge$ \\
\hline v & 11,1 & $1, \varepsilon$. & Q, r & سم سم & عرض الركبة & 9 \\
\hline$r \varepsilon, 0$ & $r$. & $r, r$ & $r V, \wedge V$ & 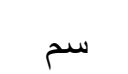 & محيط العضد & 1. \\
\hline$\Lambda \vee, O$ & $1 \cdot r$ & $\varepsilon, \cdot r$ & $q r, r$. & سم سم & محيط الصدر & 11 \\
\hline$v r$ & 19 & $\varepsilon, \varepsilon \wedge$ & $\forall \wedge, 9)$ & سم & محيط البطن & ir \\
\hline 01 & $7 \cdot, V$ & $r, \wedge)$ & $0 \leqslant, T_{0}$ & سم سم & محيط الفخذ & M \\
\hline זr & r.,o & $1, \cdot 1$ & $r \varepsilon, q$. & سم & محيط سمانة الساق & $1 \leq$ \\
\hline 11 & $1 \ldots$ & $r, 7)$ & $q r, q r$ & سم & محيط الوركين & 10 \\
\hline$r, o$ & ir & $r, \cdot r$ & $7, \vee 9$ & ملم & سمك ثنية الساعد & 17 \\
\hline r & 19 & $\{, 17$ & $V, r q$ & 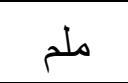 & سمك ثنية لوح الكتق & IV \\
\hline$r$ & ir & r, 97 & $V, T Y$ & ملم & سمك الثثية الحرقفية & 11 \\
\hline r & ir & $r, 10$ & 7,0 & 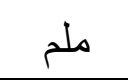 & سمك ثثية سمانة الساق & 19 \\
\hline 0,10 & $T, \sum Y$ & $\cdot, \leqslant \vee$ & 0,79 & 3 & مستوى الإنجاز & $r$. \\
\hline
\end{tabular}




\section{جدول (ץ) ( )}

معامل الارتباط البسيط بين القياسات الجسمية ومستوى الإنجاز في الوثب الطويل

\begin{tabular}{|c|c|c|c|}
\hline احتمال الخطأ & الإنجاز في الوثب الطويل & القياسات الجسمية & $ت$ \\
\hline ד ד & $\cdot, \leqslant 07-$ & وزن الجسم & 1 \\
\hline$\cdot, \cdot v_{0}$ & $\cdot$, Orr- & طول الجسم & r \\
\hline$\cdot, \cdot \leq 0$ & $\cdot, 0 \wedge 7-*$ & طول الجذع دع الرأس & r \\
\hline$\cdot, \cdot r r$ & $\cdot, T \backslash \vee-*$ & طول الذراع مع الكف & $\varepsilon$ \\
\hline$\cdot, \pi 17$ & $\cdot, \mu \backslash V-$ & طول الرجل & 0 \\
\hline$\cdot, .11$ & $\cdot, 799-*$ & طول القدم & 7 \\
\hline$\cdot, \leqslant 7 V$ & ., rTr- & عرض الكتقين & $v$ \\
\hline$\cdot, \cdots v$ & $\cdot, V \mu 1-{ }^{*} * *$ & عرض الوركين & $\wedge$ \\
\hline$\cdot, \cdot \leq 1$ &., $097-*$ & عرض الركبة & 9 \\
\hline$\cdot, .11$ & $\cdot, 799-*$ & محيط العضد & 1. \\
\hline$\cdot, r \vee q$ & $\cdot, Y \wedge \cdot-$ & محيط الصدر & 11 \\
\hline$\cdot .101$ & $\cdot, \varepsilon \leqslant 1-$ & محيط البطن & it \\
\hline$\cdot, V I Y$ & $\cdot, 119$ & محيط الفخذ & r \\
\hline$\cdot, \Gamma \wedge \wedge$ & $\cdot, r V \leq-$ & محيط الساق & $1 \leq$ \\
\hline$\cdot, 91 \pi$ & ., to & محيط الوركين & 10 \\
\hline$\cdot, 910$ & $\cdot, \ldots 7$ & سمك ثنية الساعد & 17 \\
\hline$\cdot, \leqslant 90$ & $\cdot, r 19-$ & سمك ثثية لوح الكتق & iv \\
\hline • & $\cdot, \Gamma 19$ & سمك الثنية الحرقفية & 11 \\
\hline$\cdot, 191$ & $\cdot, \varepsilon \cdot-$ & سمك ثنية سمانة الساق & 19 \\
\hline
\end{tabular}

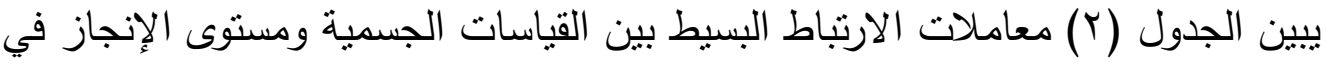

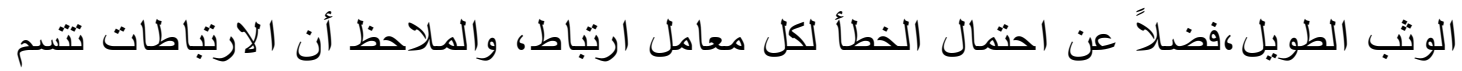

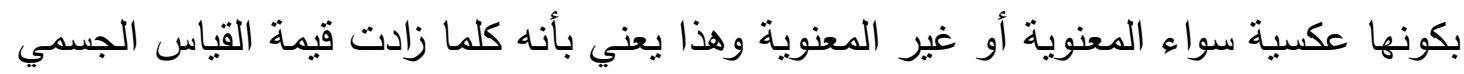
أدى ذلك الى الانخفاض في مستوى الإنجاز ، ولكون أهداف البحث تذهب الى الى ابعد من ذللك، لذاء فضل الباحث الانتقال الى الخطوة الآتيه: 
- تأثنير أطو ال الجسم في الإنجاز (*)

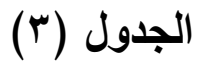

الانحدار والارتباط المتعدد ونسب مساهمة أطوال الجسم في مستوى الإنجاز بالوثب الطويل

\begin{tabular}{|c|c|c|c|c|c|c|c|}
\hline التحديد & الارتباط & الخطأ & فلمتبة & المعامل & الثقابت & القياس & الطريقة \\
\hline \multirow{5}{*}{$\cdot, 097$} & \multirow{5}{*}{$\cdot, V Y Y$} & \multirow{5}{*}{ - ro } & \multirow{5}{*}{$1, V \vee r$} & $\cdot, .09 Y-$ & \multirow{5}{*}{$|r, V| \mid$} & طول الجسم & \multirow{5}{*}{ كل الانحدارات } \\
\hline & & & & -, & & طول الجذع مع & \\
\hline & & & & $\cdot, \cdot 111$ & & طول الذراع مع & \\
\hline & & & & ., , & & طول الرجل & \\
\hline & & & & $\cdot, \cdot \mid \wedge \wedge-$ & & طول القدم & \\
\hline \multirow{2}{*}{$\cdot, 0.1$} & \multirow{2}{*}{ • } & \multirow{2}{*}{$\cdot, \cdot \varepsilon$} & \multirow{2}{*}{$\varepsilon, T \leqslant T$} & $\cdot, \cdot 1 \wedge 7-$ & \multirow{2}{*}{ r, r, } & طول الجسم & \multirow{2}{*}{ العكسي } \\
\hline & & & & $\cdot, 171-$ & & طول القدم & \\
\hline
\end{tabular}

من الجدولى. (r) و.للذي. يبين نسب مساهمة متغيرات. الأطوالل. بالإنجاز. في اللوثب العريض عن طريق معامل التحديد نلاحظ الآتي:

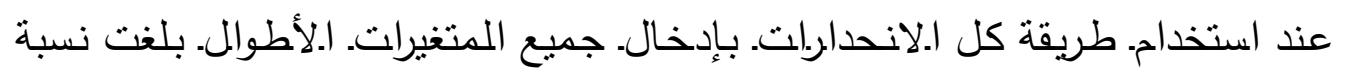

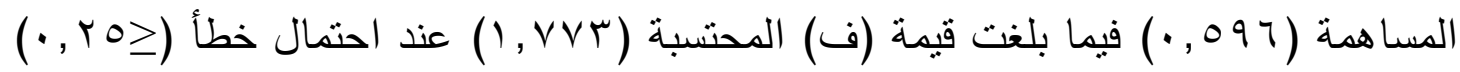

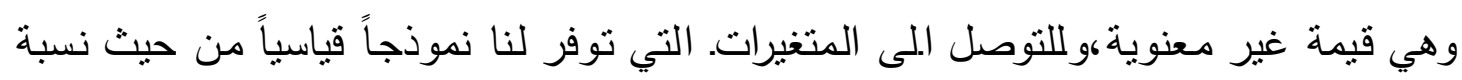

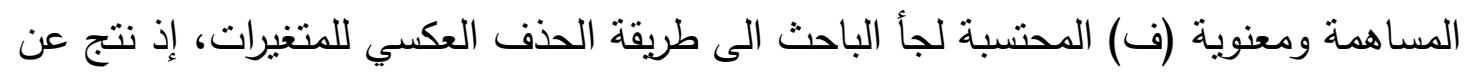

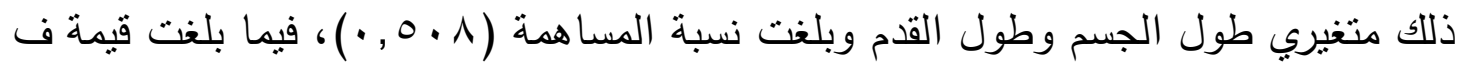

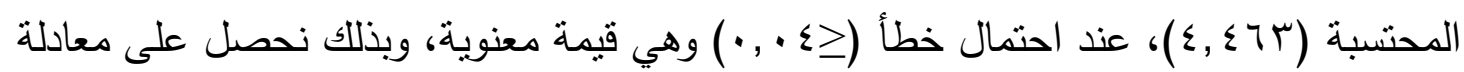

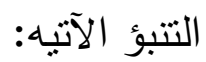

\section{(1) المعادلة}

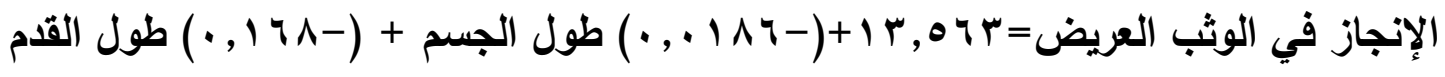

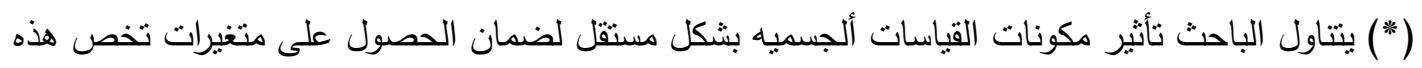
المتغيرات في شبكة الثنكل الجانبي وكما ذكر في الدراسات النظرية. 


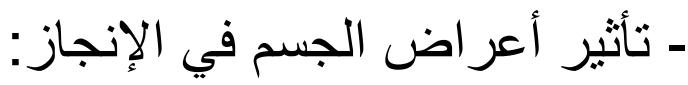

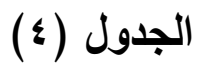

الانحدار والارتباط المتعدد ونسب مساهمة أعراض الجسم في مستوى الإنجاز بالوثب الطويل

\begin{tabular}{|c|c|c|c|c|c|c|c|}
\hline معامل & الارتباط & الخطأ & المحتسبة & المعامل & الثابت & القياس & الطريقة \\
\hline \multirow{3}{*}{$\cdot, T \cdot Y$} & \multirow{3}{*}{$\cdot, V \vee T$} & \multirow{3}{*}{$\cdot, .01$} & \multirow{3}{*}{$\varepsilon, \cdot r T$} & $\cdot, \cdot r \mid-$ & \multirow{3}{*}{11,071} & عرض الكتقين & \multirow{3}{*}{ الانحدارات } \\
\hline & & & & • & & عرض الوركين & \\
\hline & & & &., $.9 M Y-$ & & عرض الركبة & \\
\hline \multirow{2}{*}{$\cdot, 09 \mathrm{~V}$} & \multirow{2}{*}{$\cdot, V V Y$} & \multirow{2}{*}{$\cdot, ., 1$} & \multirow{2}{*}{$7,7 \times 0$} & - & \multirow{2}{*}{$1 \cdot, V Y T$} & عرض الوركين & \multirow{2}{*}{ العكسي } \\
\hline & & & &., $.999-$ & & عرض الركبة & \\
\hline
\end{tabular}

من الجدول (ع) والذي يبين نسب مساهمة متغيرات الأعراض في الإنجاز في الوثب العريض عن طريق معامل التحديد نلاحظ الآتي:

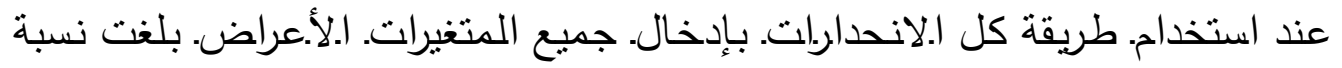

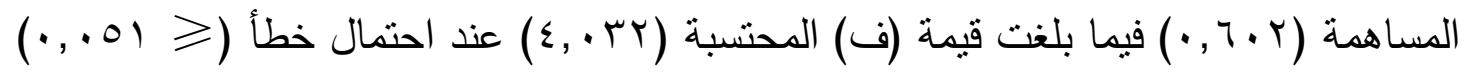

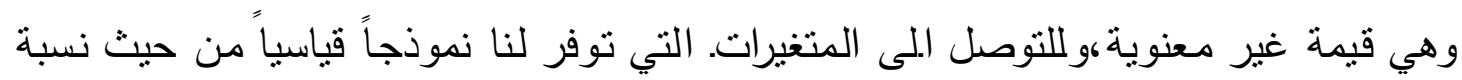

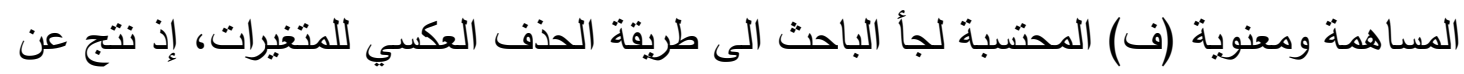
ذلك متغيري عرض الوركين وعرض الركبة وبلغت نسبة المساهمة (ه9 ه • ))، فيما بلغت قيمة

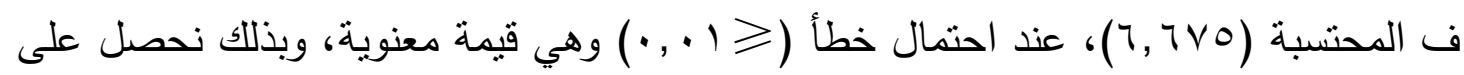

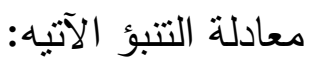

المعادلة (r)

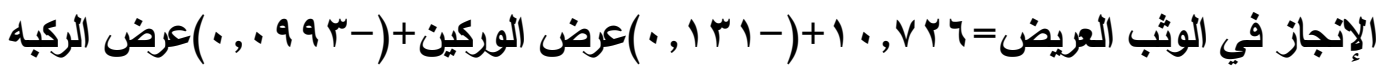


- تأثير وزن الجسم ومحيطاته في الإنجاز :

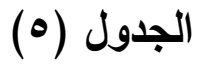

الانحدار والارتباط المتعدد ونسب مساهمة الوزن ومحيطات الجسم في مستوى الإنجاز بالوثب الطويل

\begin{tabular}{|c|c|c|c|c|c|c|c|}
\hline التصديد & الارتباط & الخطأ & المتسبة & المعامل & الثابت & القياس & الطريقة \\
\hline \multirow{7}{*}{$\cdot, 9 \cdot r$} & \multirow{7}{*}{$\cdot, 901$} & \multirow{7}{*}{ r } & \multirow{7}{*}{$0, r \leqslant A$} & $\cdot, \cdot T \leqslant-$ & \multirow{7}{*}{$r, r V \varepsilon$} & الوزن & \multirow{7}{*}{ الانددارات } \\
\hline & & & &., $109-$ & & محيط العضد & \\
\hline & & & &., $10 \mathrm{~V}$ & & محيط الصدر & \\
\hline & & & & ., $1 \Gamma \leq-$ & & محيط البطن & \\
\hline & & & &., .911 & & محيط الفخذ & \\
\hline & & & & $\cdot, \cdot V Y-$ & & محيط سمانة الساق & \\
\hline & & & & $\cdot, \cdot r r \varepsilon$ & & محيط الوركين & \\
\hline \multirow{6}{*}{$\cdot, \wedge 97$} & \multirow{6}{*}{$\cdot, 9 \leq 7$} & \multirow{6}{*}{$\cdot, \cdot r \varepsilon$} & \multirow{6}{*}{$V, 17 r$} & $\cdot, \ldots 9 \vee-$ & \multirow{6}{*}{ r,VIV } & وزن الجسم & \multirow{6}{*}{ العكسي } \\
\hline & & & &., $171-$ & & محيط العضد & \\
\hline & & & & $\cdot, I T V$ & & محيط الصدر & \\
\hline & & & & .,1Y7- & & محيط البطن & \\
\hline & & & &., 1 \% & & محيط الفذذ & \\
\hline & & & & $\cdot, \cdot$ VOA- & & محيط سمانة الساق & \\
\hline
\end{tabular}

من الجدولى. (0) وللذي. يبين نسب مساهمة متغيرات. الموزن. وللمحيطات. الجسم في الإنجاز في الوثب العريض نلاحظ الآتي:

عند استخدام طريقة كل الانحدارات بإدخال متغيرات الوزن ومحيطات الجسم بلغت نسبة

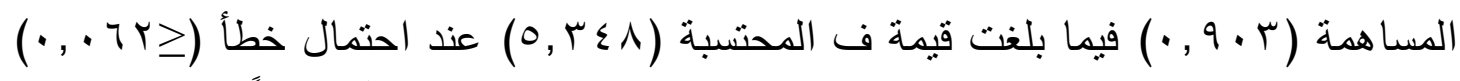

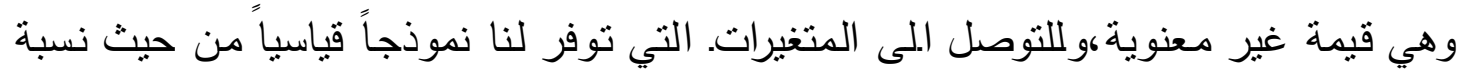

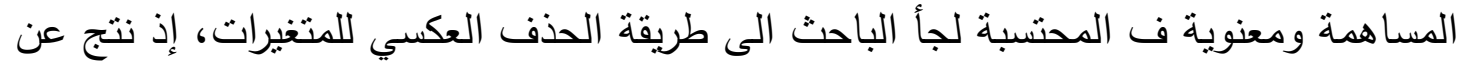

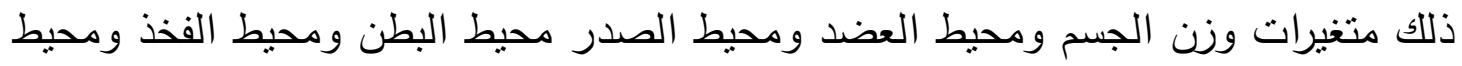

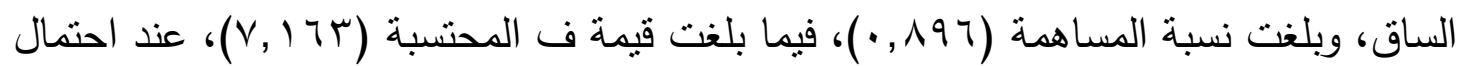

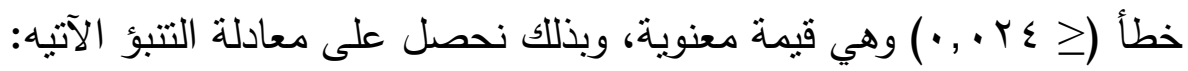
المعادلة (r)

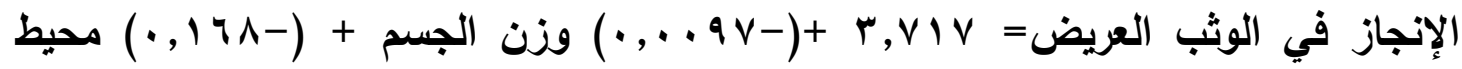

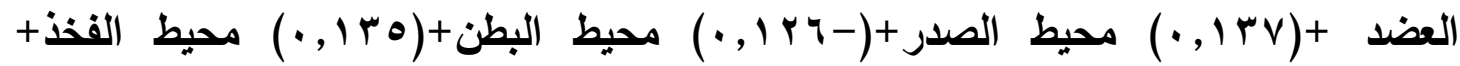

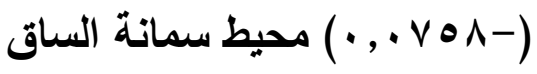


- تأثير سمك الثنايا الدهنية للجسم في الإنجاز :

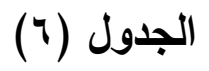

الانحدار والارتباط المتعدد ونسب مساهمة سمك الثنايا الجلدية في مستوى الإنجاز بالوثب

الطويل

\begin{tabular}{|c|c|c|c|c|c|c|c|}
\hline التحديد & الارتباط & الخطأ & المحتسبة & المعامل & الثقابت & القياس & الطريقة \\
\hline \multirow{4}{*}{ E } & \multirow{4}{*}{., $\vee 9}$. & \multirow{4}{*}{$\cdot, 1 \cdot \varepsilon$} & \multirow{4}{*}{$r, q}$. & & \multirow{4}{*}{$0, \cdot 11$} & سمك ثنية & \multirow{4}{*}{ الانحدارات } \\
\hline & & & & $\cdot|V|-$ & & سمك ثنية لوح & \\
\hline & & & & •, YMY & & سمك الثثية & \\
\hline & & & & $\cdot, \cdot+10$ & & سمانة الساق ثنية & \\
\hline \multirow{3}{*}{ T. } & \multirow{3}{*}{ - $\vee \vee \vee$} & \multirow{3}{*}{$\cdot, \cdot \leqslant q 9$} & \multirow{3}{*}{$, 1,7$} & E & \multirow{3}{*}{$0,19 \varepsilon$} & سمك ثثية & \multirow{3}{*}{ الانحسار } \\
\hline & & & & $\cdot, 1 \leq \cdot-$ & & سمك ثنية لوح & \\
\hline & & & & $\cdot, 1 \wedge 1$ & & سمك ثثية & \\
\hline
\end{tabular}

من الجدول (7) والذي يمثل نسب مساهمة متغيرات سمك الثنايا الجلدية في الإنجاز

للوثب العريض نلاحظ الآتي:

عند استخدام. طريقة كل الانحدار.ات. بإدخال. جميع المتغيرات. بلغت نسبة المساهمة

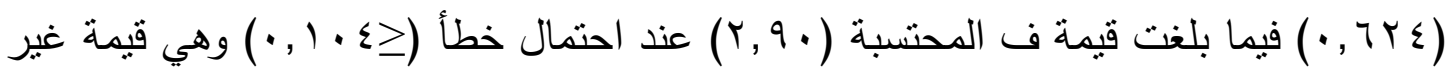

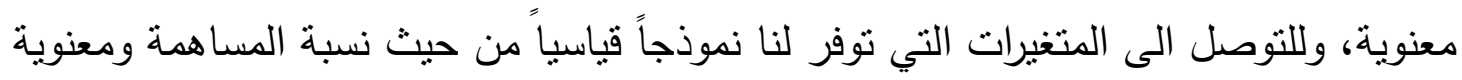
ف المتسبة لجأ الباحث الى طريقة الحذف العكسي للمتغيرات، إذ نتج عن ذلك متغيرات سمك فئك

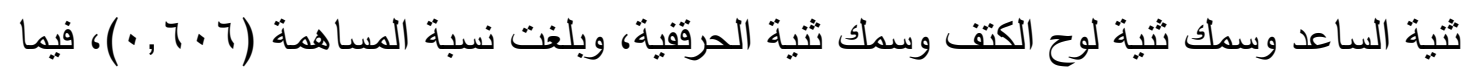

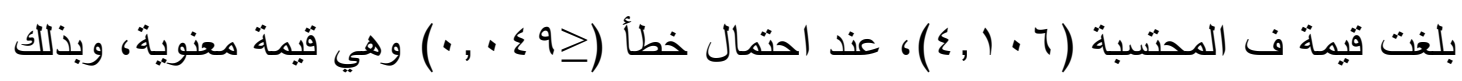
نحصل على معادلة التتبؤ الآتية:

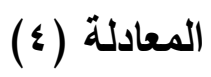

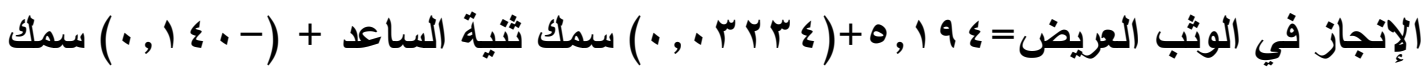
ثنية لوح الكتف + (111) , •) سمك الثنية الحرقفية YrI 
- أفضل المتغير ات المؤثرة في الإنجاز:

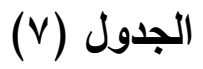

الاندار الانتقائي للمتغيرات المرشحة عن معادلات التنبؤ في الإنجاز بالوثب الطويل

\begin{tabular}{|c|c|c|c|c|c|c|}
\hline التصديد & البسيط & ف المحتسبه & المعامل & الثقابت & القياس & الطريقة \\
\hline \& \& OT & •,VTI & $11, \leqslant \leq 9$ & 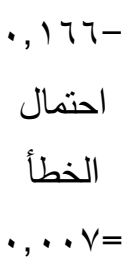 & 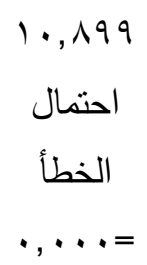 & عرض الوركين & الانتقائي \\
\hline
\end{tabular}

من الجدول (V) ولأجل التوصل الى أفضل متغير يمكن أن يؤثر في الإنجاز ، تم اللجوء

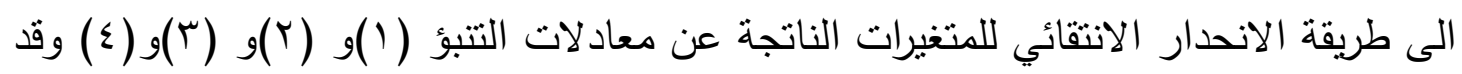

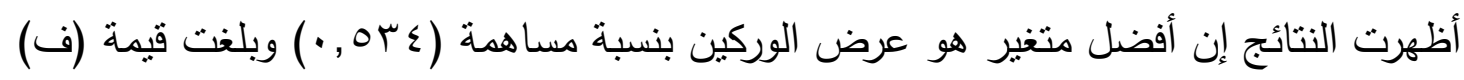

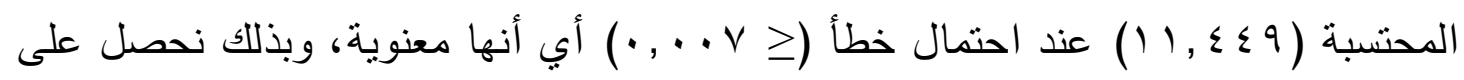
معادلة التتبؤ الآتية:

(•) المعادلة

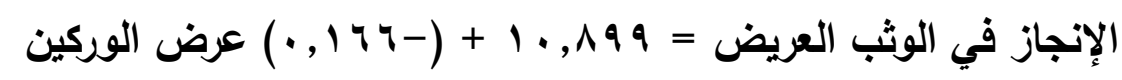

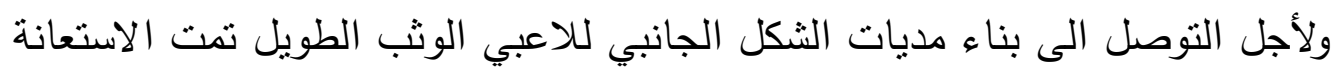

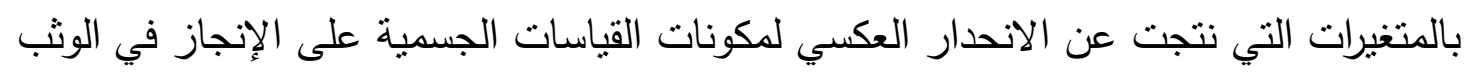

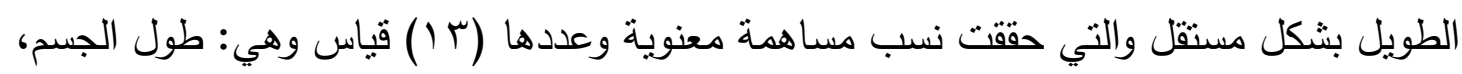

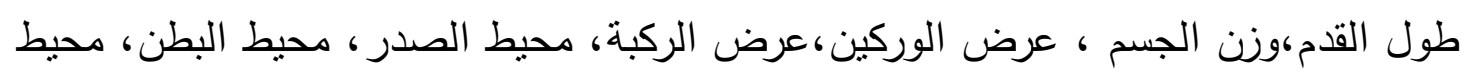

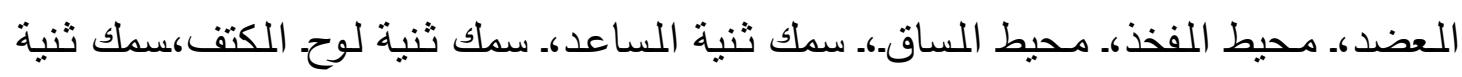

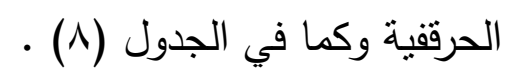
مناقشة وتحليل : من خلال ما تقام، ومن خلال تتاول متغيرات القياسات الجسمية وفقاً لمكوناتها، وعند استخدام طريقة الحذف العكسي The Back ward Elimination Procedure والتي تقوم على أساس حذف المتغيرات الغير المهمة بالتدريج مع إعطاء نموذج معنوي للقياسات الجسمية

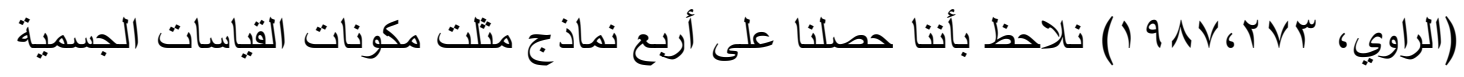

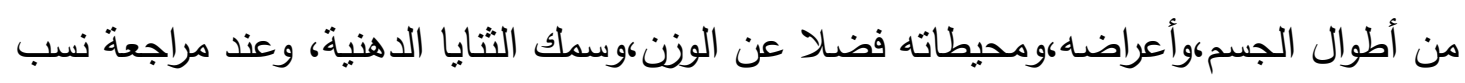


مساهمتها نجد بأن هذه النماذج قد أعطت نسب مساهمه عالية تراوحت بين ( (0, • - - م, • )،

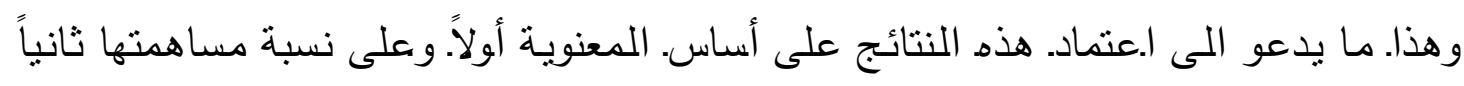

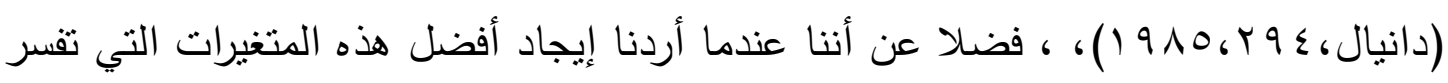
Stepwise

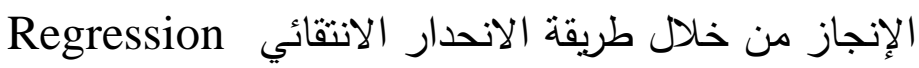
ظrocedure أو الفروق الفردية لدى عينة البحث في الإنجاز بنسبة (ع بهo , ·).

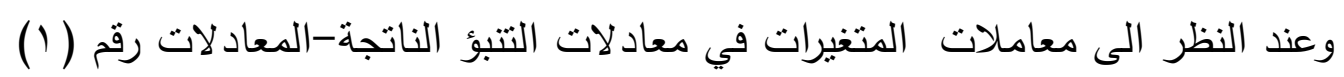

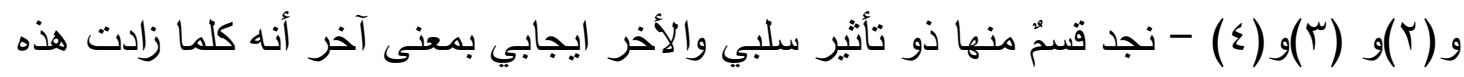
المتغيرات في قيمها وحدة واحدة انخفض أو أرتفع الإنجاز بنفس قيمة المعامل وفقاً لنوع الإثنارة

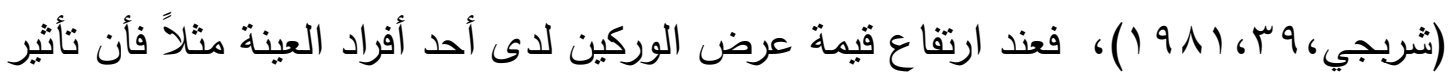

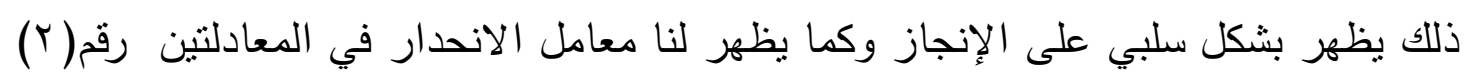

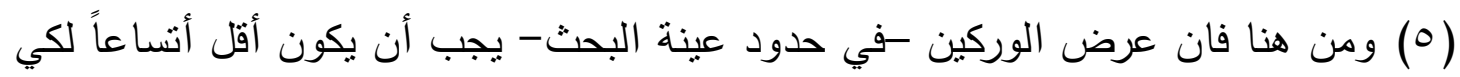

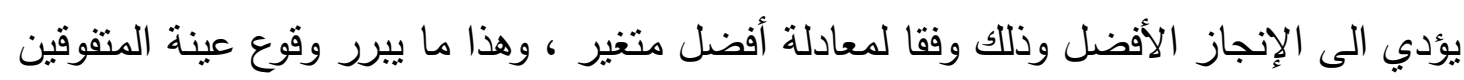

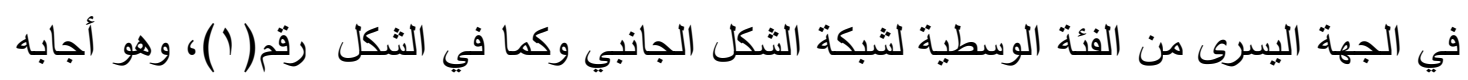

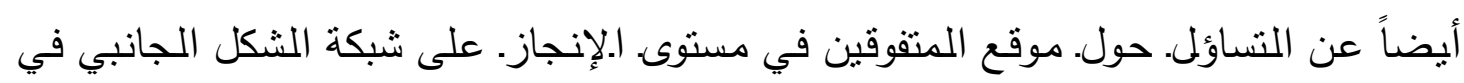

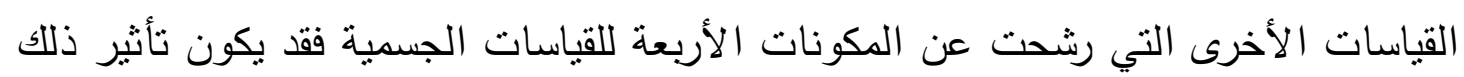

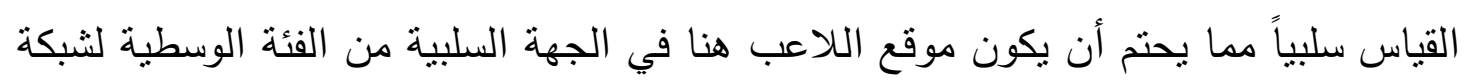

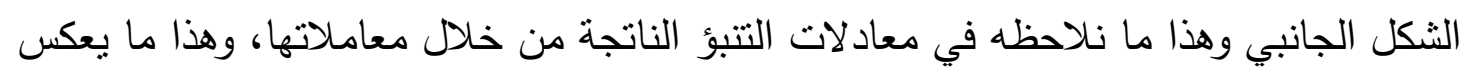

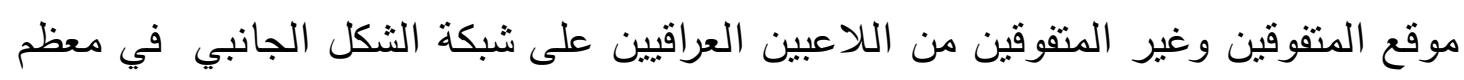

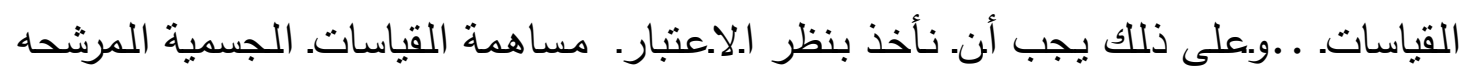

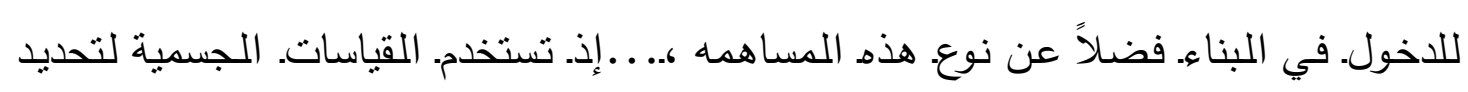

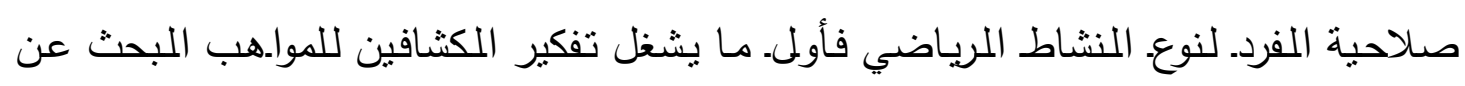
الخامات الرياضية المثمره والمبشرة بالتفوق الرياضي وأدواتهم في هذه العملية هي القياسات

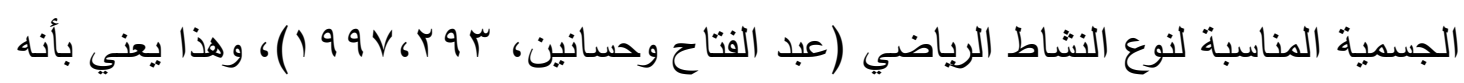

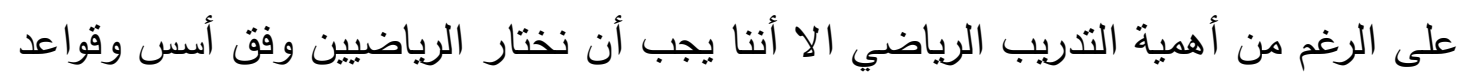

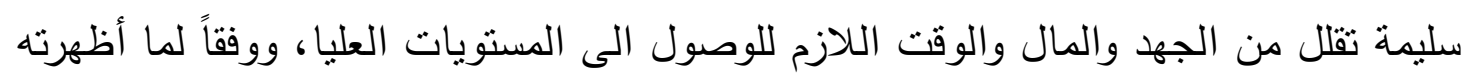

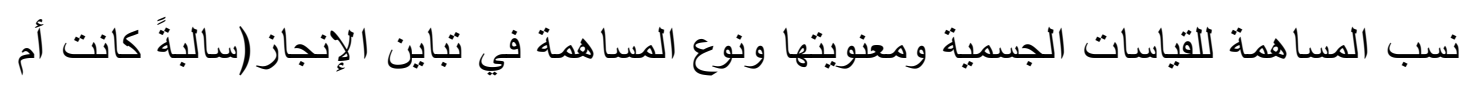

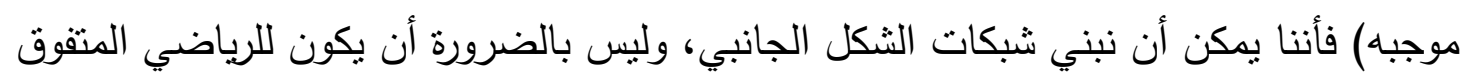

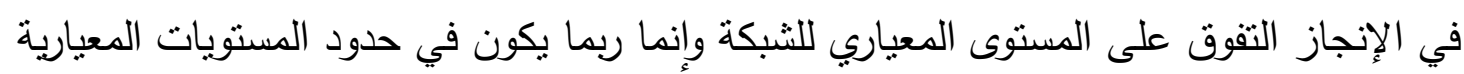
الأقل من المتوسط العام (سـه , • ع) ،وبذلك تكون نتائج هذا البحث قد خالفت جميع نتائج 
البحوث التي هدفت الى إيجاد شبكة الثكل الجانبي للمتفوقين وغير المتفوقين، وربما تأتي هذه

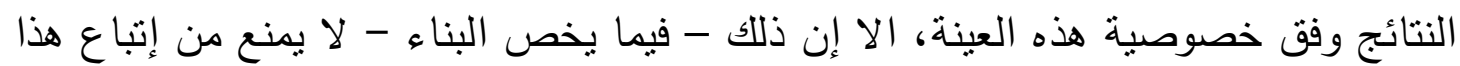
الأسلوب عند إيجاد شبكة الثكل الجانبي لعينات أخرى.

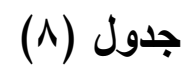

القيم المحسوية لمديات شبكة الثكل الجانبي للقياسات الجسمية المؤثرة في مستوى الإنجاز

للوثب الطويل

\begin{tabular}{|c|c|c|c|c|c|c|c|c|c|}
\hline الانحراف & الحسابي & س - أقل من & 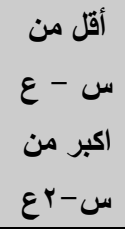 & س أقل من -ه · ع ع & س & س أكبر من & س أكبر من & س أكبر من & الجسمية \\
\hline $0, r_{1}$ & $v \cdot, v o$ & فأَّل, •T & $\begin{array}{l}T 0,0 \leqslant \\
T, r, r\end{array}$ & $\begin{array}{l}71,1 \leq 0 \\
70,0 \leqslant\end{array}$ & $\begin{array}{l}r,, 1 \leq 0 \\
V T, \text { ror }\end{array}$ & $\begin{array}{l}V T, Y 04 \\
V T, Y 00\end{array}$ & $\begin{array}{l}V 7, r 00 \\
11,070\end{array}$ & $\begin{array}{c}1,070 \\
\text { فأكثر } 010\end{array}$ & وزن الجسم \\
\hline$\varepsilon, \varepsilon \varepsilon$ & IVV, qY & ع ـ ـ 179 & $\begin{array}{l}1 \vee r, \varepsilon \wedge \\
179, \cdot \varepsilon\end{array}$ & $\begin{array}{l}\text { IVO,V } \\
\text { IVT, \&A }\end{array}$ & $\begin{array}{l}1 \times 0, v \\
1 \wedge \cdot, 1 \varepsilon\end{array}$ & $\begin{array}{l}11 \cdot, 1 \leq \\
\mid A r, r 4\end{array}$ & $\begin{array}{l}\text { IAr,ru } \\
\text { IAT,A }\end{array}$ & فأكثر 1 1 1 1 1 & الجسم \\
\hline 1,74 & $r V, 11$ & فأقل 97 & $\begin{array}{l}\text { YO,Tr } \\
r T, 9 T\end{array}$ & $\begin{array}{l}r, Y \Lambda \\
\text { ro,Tr }\end{array}$ & $\begin{array}{l}r q, Y \wedge \\
r V, q \leq\end{array}$ & $\begin{array}{l}r V, q \varepsilon \\
Y \wedge, Y Y\end{array}$ & $\begin{array}{l}r \wedge, V V \\
r \cdot, \Sigma r\end{array}$ & فأكثر & طول القام \\
\hline$r, \cdot v$ & $r, r \varepsilon$ & $\begin{array}{l}\text { فأقل } \\
\text { فV, }\end{array}$ & $\begin{array}{l}r q, r v \\
r v, r\end{array}$ & $\begin{array}{l}r \cdot, r . \\
r q, r v\end{array}$ & $\begin{array}{l}r \cdot, r . \\
r, r v\end{array}$ & 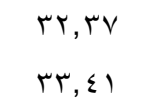 & $\begin{array}{l}r T, \Sigma) \\
r 0, \Sigma \wedge\end{array}$ & 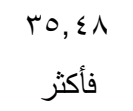 & الوركين \\
\hline $1, \varepsilon$. & $9, r r$ & فأقلّ & $\begin{array}{l}V, q r \\
7, \text { or }\end{array}$ & $\begin{array}{l}\lambda, T r \\
V, q r\end{array}$ & $\begin{array}{l}\Lambda, T r \\
1 \cdot, \cdot r\end{array}$ & $\begin{array}{l}1 \cdot, \cdot r \\
1 \cdot, V r\end{array}$ & $\begin{array}{l}I \cdot, V Y \\
I r, K r\end{array}$ & فأكثر & عرضة \\
\hline$\varepsilon, \cdot r$ & $q Y, r$ & $\begin{array}{l}\wedge \leq, 17 \\
\wedge,, 1 \leq\end{array}$ & $\begin{array}{l}\wedge \wedge, 1 \wedge \\
\wedge \leq, 1\rceil\end{array}$ & $\begin{array}{l}9 \cdot, 19 \\
1 \wedge, 11\end{array}$ & $\begin{array}{l}9 \cdot, 19 \\
9 \leq, Y 1\end{array}$ & $\begin{array}{l}9 \leq, Y) \\
97, r Y\end{array}$ & $\begin{array}{l}97, r r \\
1 \ldots, r \leq\end{array}$ & $\begin{array}{l}\cdots, r \leq \\
1 \cdot \leq, r y\end{array}$ & الصدر \\
\hline$\varepsilon, \varepsilon \wedge$ & $\forall \wedge, q)$ & فأقل 79,90 & $\begin{array}{l}V \leq, \leq r \\
79,90\end{array}$ & $\begin{array}{l}V 7, T V \\
V \varepsilon, \varepsilon T\end{array}$ & $\begin{array}{l}V 4, T V \\
11,10\end{array}$ & $\begin{array}{l}11,10 \\
1 \Gamma, 9 \pi\end{array}$ & $\begin{array}{l}\wedge r, q r \\
\wedge V, \wedge V\end{array}$ & $\begin{array}{c}\text { فأكثر } \\
\text { فأر }\end{array}$ & محيط البطن \\
\hline$r, r$ & $T V, A V$ & فأقل & $\begin{array}{l}r O, O V \\
r r, Y V\end{array}$ & $\begin{array}{l}r Y, V Y \\
r O, O V\end{array}$ & $\begin{array}{l}r q, V r \\
r q, \cdot r\end{array}$ & $\begin{array}{l}r q, \cdot r \\
r \cdot, r v\end{array}$ & $\begin{array}{l}r \cdot, I V \\
r r, \leqslant V\end{array}$ & 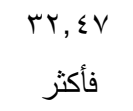 & محيط \\
\hline$r, \wedge)$ & $0 \leqslant, r_{0}$ & 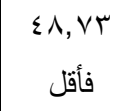 & $\begin{array}{l}01,0 \leqslant \\
\varepsilon \Lambda, V \Psi\end{array}$ & $\begin{array}{l}0 Y, 9 \leqslant 0 \\
01,0 \leqslant\end{array}$ & $\begin{array}{l}0 Y, 9 \leq 0 \\
00, Y 00\end{array}$ & $\begin{array}{l}00,100 \\
\text { OV, } 17\end{array}$ & $\begin{array}{l}\text { OV, } 17 \\
\text { Oq, 9V }\end{array}$ & 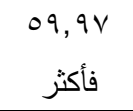 & محيط الفذذ \\
\hline $1, \cdot 1$ & $r \leqslant, q$. & $\begin{array}{c}r \text { Tأقل } \\
\text { فأق }\end{array}$ & $\begin{array}{l}r r, A r \\
r r, V \varepsilon\end{array}$ & $\begin{array}{l}r \varepsilon, \Gamma T \\
r, \wedge T\end{array}$ & $\begin{array}{l}r \varepsilon, r u \\
r_{0, \varepsilon}\end{array}$ & $\begin{array}{l}r_{0}, \varepsilon \varepsilon \\
r_{0,91}\end{array}$ & $\begin{array}{l}r 0,91 \\
r v, \cdot T\end{array}$ & 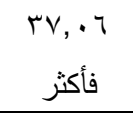 & سمانة الساق \\
\hline$r, \cdot r$ & $7, \vee 9$ & $\begin{array}{l}\text { فأقل r,vo } \\
\text { فأق }\end{array}$ & $\begin{array}{l}\varepsilon, V V \\
r, V_{0}\end{array}$ & $\begin{array}{l}0, V A \\
\varepsilon, V V\end{array}$ & $\begin{array}{l}0, \vee \wedge \\
\vee, \wedge\end{array}$ & $\begin{array}{l}\vee, \wedge \\
\wedge, \wedge\end{array}$ & $\begin{array}{l}\wedge, \wedge 1 \\
1 \cdot, \wedge r\end{array}$ & فأكثر & سمك ثنية \\
\hline 1,91 & $V, 9 r$ & $\begin{array}{l}r, 97 \\
\text { فأقل } 97\end{array}$ & $\begin{array}{l}0,9 \leq \\
r, 97\end{array}$ & $\begin{array}{l}7,95 \\
0,9 \leqslant\end{array}$ & $\begin{array}{l}7,94 \\
\wedge, 91 \\
\end{array}$ & $\begin{array}{l}\wedge, 9) \\
9,9\end{array}$ & $\begin{array}{c}9,9 \\
11,11 \\
\end{array}$ & فأكثر 1 , 1 1 & سوح الكتف ثنية \\
\hline$r, 97$ & $V, r q$ & فأقل & $\begin{array}{l}0, Y V \\
\varepsilon, Y_{0}\end{array}$ & $\begin{array}{l}7,0 Y \\
0, Y Y\end{array}$ & $\begin{array}{l}7,0 \text {. } \\
1, .0\end{array}$ & $\begin{array}{l}\Lambda, .0 \\
\wedge, \lambda 1\end{array}$ & $\begin{array}{l}\wedge, \wedge \\
1 \cdot, r r\end{array}$ & فأكثر, • & سمك الثنية \\
\hline
\end{tabular}

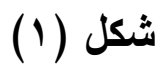

Yr纟 
شبكة الثكل الجانبي للقياسات الجسمية المؤثرة في الإنجاز للاعبين

المتفوقين وغير المتفوقين بالوثب الطويل

\begin{tabular}{|c|c|c|c|c|c|c|c|c|c|}
\hline س - أقل من & س أقل من - ع ع سن & س أكبل من من - ع ع & $\begin{array}{c}\text { س } \\
ع \cdot, \bullet \pm\end{array}$ & س أكبر من & س س أكبر من + عن & س أكبر من & سلتفوقين & س - المتفوقين & الجسمية \\
\hline & • & & - & & & & $\vee r, \wedge \Lambda$ & $T \&, r \Psi$ & وزن الجسم \\
\hline & & - & • & & & & $\vee \vee \wedge, \wedge \wedge$ & ivo & طول الجسم \\
\hline & $\bullet$ & & $\bullet$ & & & & $r V, \leqslant V$ & $r O, Y$. & طول القدم \\
\hline & - & & $\bullet$ & & & & ry,,$A$ & $r q, 1$. & لوركين \\
\hline & & - & - & & & & $9,0 \wedge$ & $\Lambda, O H$ & عرضة الركبة \\
\hline & & • & $\bullet$ & & & & 94,11 & $\wedge 9,0$ & محبط \\
\hline & & - & - & & & & A., l. & $v_{0, \mu r}$ & محبط \\
\hline & & - & $\bullet$ & & & & $r \wedge, 0$ & צ & محيط \\
\hline & & & $\bullet$ & & & & $0 \leqslant, \cdot r$ & $\Delta \Delta, r \mu$ & محيط \\
\hline & & & $\bullet$ & & & & $r \leqslant, q r$ & $r \leq, \wedge r$ & سمانة \\
\hline & & - & $\bullet$ & & & & 8,14 & 0,74 & سمك ثنية \\
\hline & & • & & & - & & T,AT & $1 \cdot, r \mu$ & لوح الكتف ثنية \\
\hline & & - & • & & & & $\curlyvee, \wedge \wedge$ & $0, r r$ & سمك الثنية \\
\hline
\end{tabular}

• المتفوقون

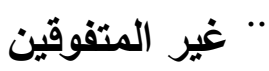

\section{rro}




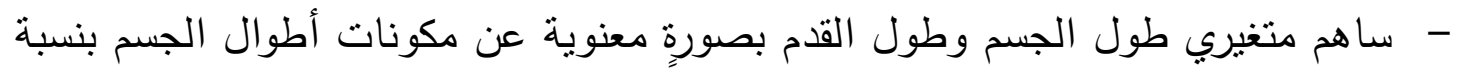

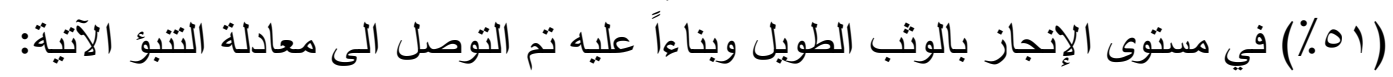

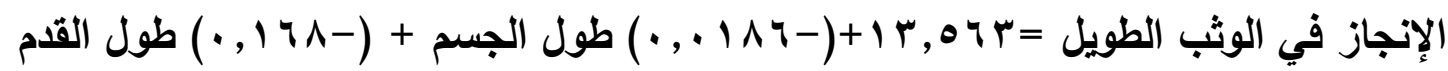

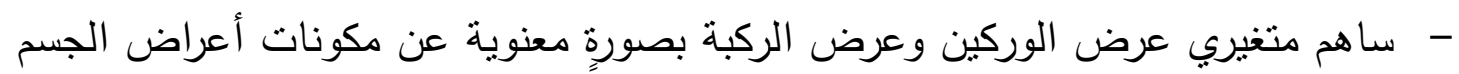

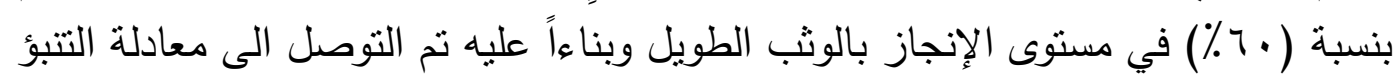

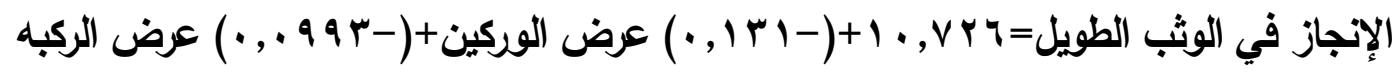

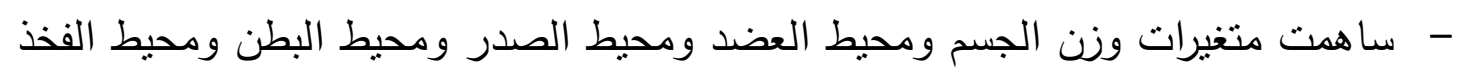

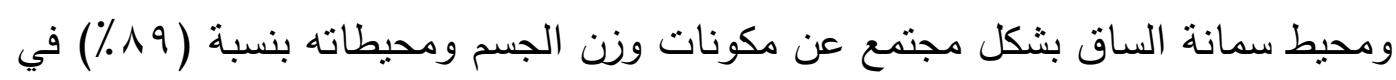

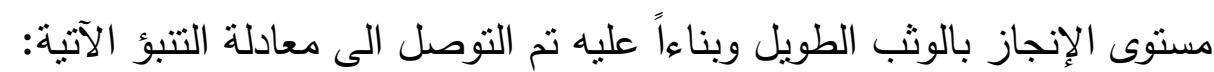

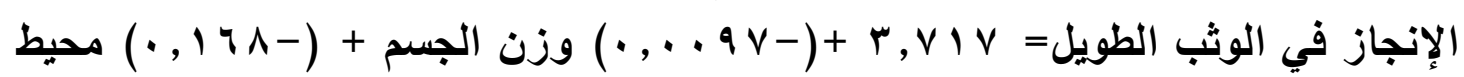

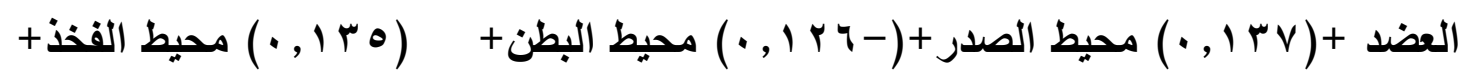

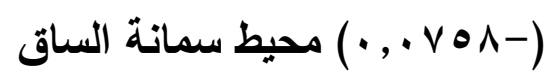
- ساهمت متغيرات سمك ثثية الساعد وسمك ثثية لوح الكتق وسمك ثثية الحرقفية عن مكونات

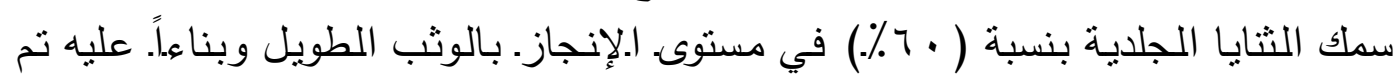
التوصل الى معادلة التنبؤ الآتية:

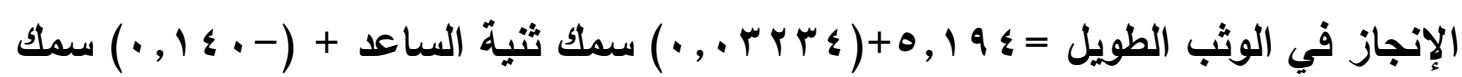

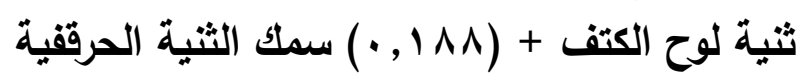

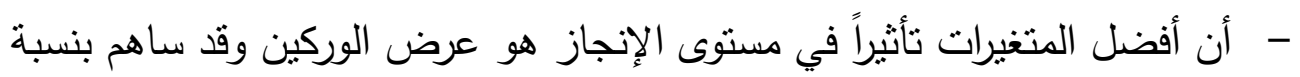

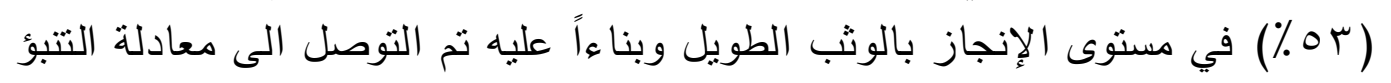
الآتية:

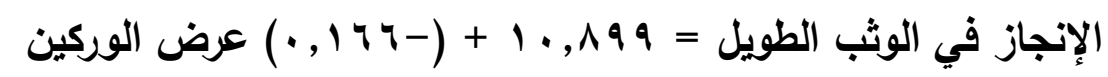

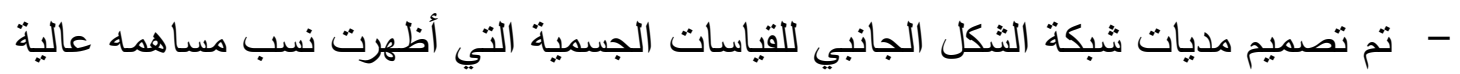

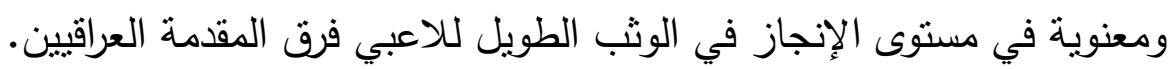

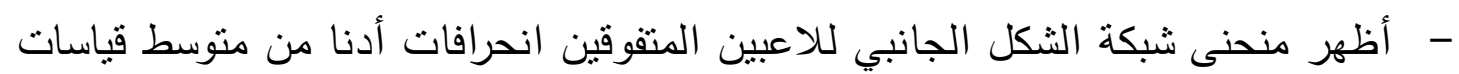

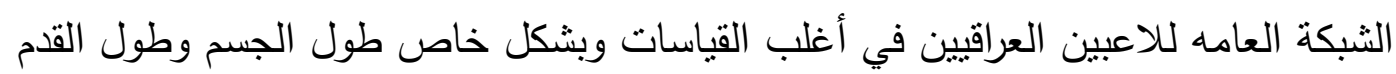

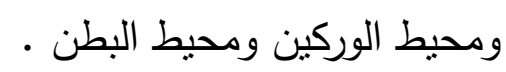

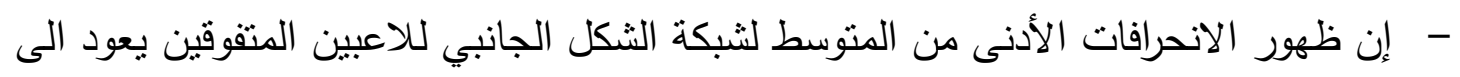

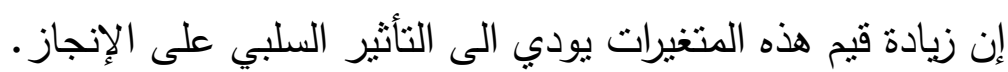




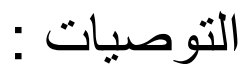

- الأخذ بنظر الاعنبار معادلات التتبؤ الني نم التوصل اليها كوسيلة لتقويم وتوجيه العملية

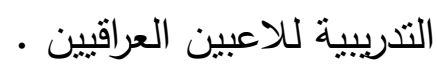
- الأخذ بنظر الاعتبار معادلات التتبؤ التي نم التوصل اليها في عملية انتقاء لاعبي الوثب

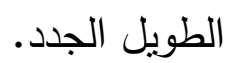
- - يجب ملاحظة شبكة الثكل الجانبي للمتفوقين وغير المتفققين من اللاعبين العراقيين في الوثب الطويل ومحاولة معالجة الخلل الناتج في مواقع بعض القياسات الجسمية على الثبكه

- - عند إيجاد شبكة الثنكل الجانبي يجب مراعاة مدى مساهمة المتغيرات المختارة في مستوى الإنجاز للعينة الني تصمم لها الثبكة وذللك لزيادة فاعلية التقويم.

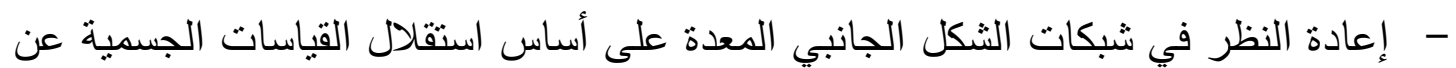
مستوى الإنجاز في الدراسات التي سبق إجرائها. - - ضرورة إعادة إجراءات البحث على الفعاليات الأخرى.

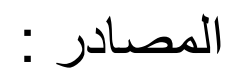
- - إبراهيم، مروان عبد المجيد(999 (1):الاختبارات والقياس والتقويم في التربية الرياضية، دار الفكر العربي، القاهرة. - - بسطويسي، احمد بسطويسي(999 (1):أسس ونظريات التدريب الرياضي، دار الفكر العربي،

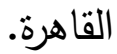
- التكريتي، وديع ياسين والعبيدي، حسن محمد(999 (1)): التطبيقات الإحصائية في بحوث التربية الرياضية، طب،دار الكتب للطباعة والنشر ،جامعة الموصل.

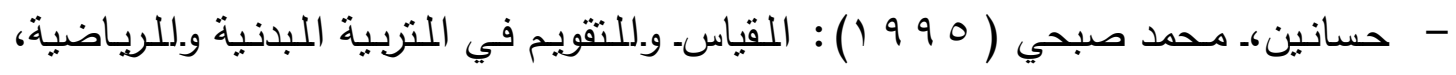
جrابطا،دار الفكر العربي، القاهرة - - حسن، دلال علي (99V1): تصميم الثكل الجانبي (البروفيل) في بعض القياسات الجسمية والفسيولوجية والعقلية للاعبات المتميزات في كرة السلة، بحث منشور في المجلة العلمية

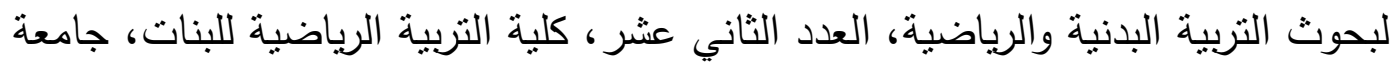

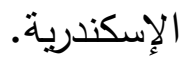

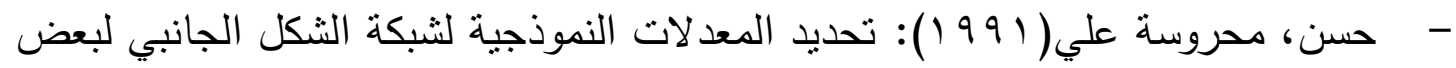
القياسات الجسمية لتحقيق المستوى العالي للاعبي سلاح الثيش بالمبارزة،بحث منشور في 
المجلة العلمية لبحوث التربية البدنية والرياضية، المجلد الثالث عشر ، العدد الأول، دراسات وبحوث، جامعة حلوان، الإسكندرية.

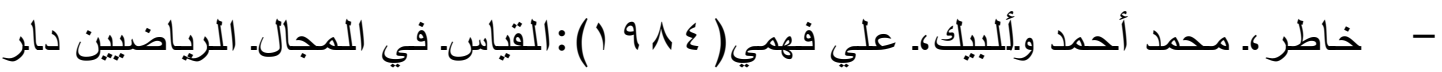
المعارف، القاهرة. - - الخياط،ضياء قاسم و علاوي، ثيلام يونس(9 9 9 ()): القياسات الجسمية كدالة للتنبؤ بالقوة الانفجارية للاعبي كرة اليد، بحث منشور ، مجلة الرافدين للعلوم الرياضية، العدد السابع، لياهل

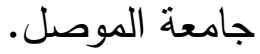
- - دانيال، واين (910 (1): الإحصاء الحيوي أساس للتحليل في العلوم الصحية، (ترجمة زياد رشاد عبد الله)، مطابع جامعة الموصل.

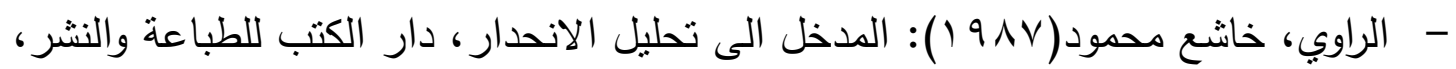

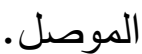
- رضوان، محمد نصر الدين (999 (1):المرجع في القياسات الجسمية،ط (،دار الفكر العربي،

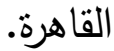
- شربجي،عبد الرزاق محمد صلاح( (191)):الانحدار الخطي المتعدد،دار الكتب للطباعة،

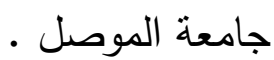

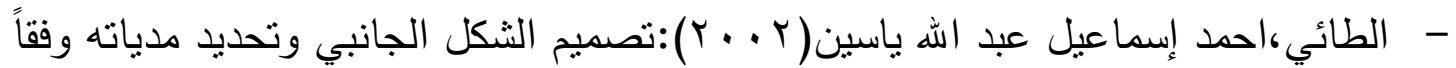

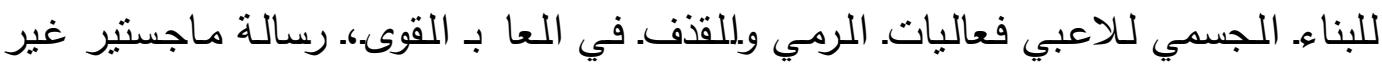
منشورة، كلية التربية الرياضية، جامعة الموصل.

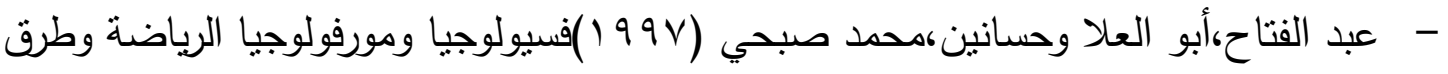
القياس للتقويم، طا، دار الفكر العربي، القاهرة.

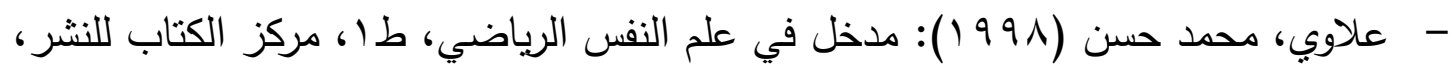

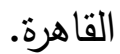
- علاوي، محمد حسن ورضوان، محمد نصر( · . . ب): القياس في التربية الرياضية وعلم النفس الرياضي، طس، دار الفكر العربي، القاهرة.

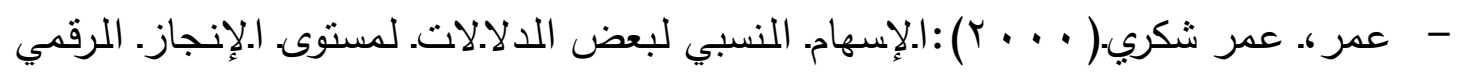

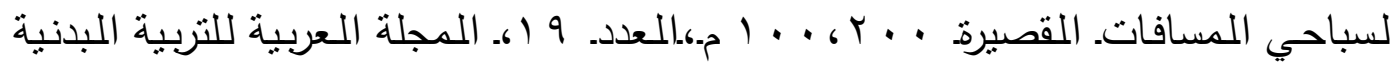
والرياضية، كلية التربية الرياضية للبنات، جامعة الإسكندرية. - عنان، محمود عبد الفتاح(ب 9 (1):دراسة لتحديد بعض المواصفات الجسمية والنمط المميز لسباحي المسافات، المؤتمر العلمي لبحوث ودراسات التربية البدنية والرياضية، جامعة حلوان

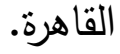


- قلادة، بياتريس روفائيل والثاذلي، ماجدة صلاح ( • 99 ()): التتبؤ بمستوى القدرات الحركية

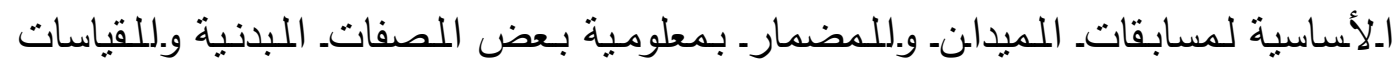
الانثروبومترية لمنتخب فريق اللياقة البدنية بجمهورية مصر العربية، المؤتمر العلمي الأول، المجلد الأول، دور التربية الرياضية في حل المشكلات المعاصرة، جامعة الزقازيق، كلية التربية الرياضية للبنات. مصر.

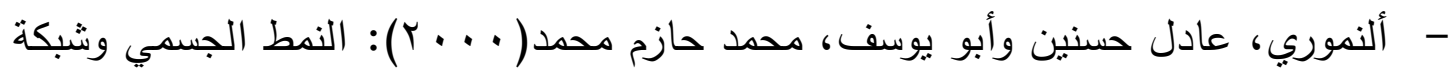

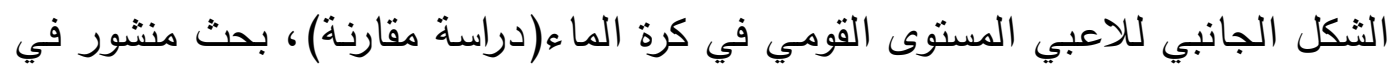

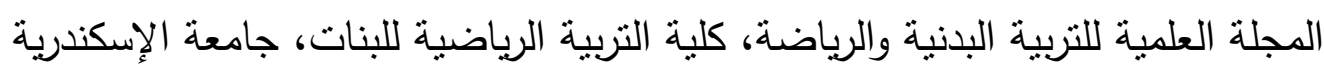

- Kir knedal, D and others ,(1987): Measurement and evaluation for physical Education ,2 ed ,Human kinetics publisher ,Inc ,Illumes.

- Mathews, D.K(1978):Measurement physical Education, 5thed, Philadelphia W.B Saunders Co . 